\title{
Os limites da contribuição da indústria ao desenvolvimento nos períodos Lula e Dilma: uma nova versão do industrialismo periférico? *
}

\author{
Antônio Carlos Diegues **
}

\begin{abstract}
Resumo
O objetivo deste artigo é analisar os limites da contribuição da indústria brasileira ao desenvolvimento em dois momentos qualitativamente distintos: o ciclo de relativa pujança entre 2003-2010 e a desaceleração e reversão entre 2011 e 2015 . A partir deste esforço, pretende-se estabelecer um diálogo com a obra de Wilson Cano - principalmente com suas reflexões na última década - em três dimensões. A primeira delas refere-se à maneira em que estas reflexões compreendem o desenvolvimento como um processo histórico. A segunda diz respeito à heterogeneidade estrutural característica do subdesenvolvimento e a compreensão da industrialização como uma condição necessária para se buscar contornar a dinâmica de reprodução deste processo. Por fim, busca-se compreender os limites da contribuição da indústria ao desenvolvimento ao dialogar com a interpretação presente em toda a obra do autor acerca da centralidade de um projeto de desenvolvimento nacional como vetor de tal estratégia. Na dimensão empírica, para se compreender os limites das contribuições da indústria brasileira entre 2003 e 2015, utiliza-se a metodologia de decomposição estrutural, a fim de se mensurar tal contribuição em três dimensões: (i) produtividade, (ii) salários e remuneração média e (iii) sofisticação das exportações em relação às importações. Como resultados, o artigo traz elementos que sugerem a consolidação de um padrão de organização estrutural da indústria brasileira que limita sua capacidade de contribuição ao desenvolvimento independentemente dos econômicos domésticos. Esses limites seriam materializados na incapacidade de se engendrar um ciclo de desenvolvimento virtuoso que viabilizasse a reconfiguração da estrutura produtiva. Por fim, conclui-se que os limites estariam associados ao fenômeno que este artigo sugere que seja interpretado como uma nova versão do industrialismo periférico (e agora regressivo).
\end{abstract}

Palavras-chave: Cano, Wilson, 1937-2020, Indústria, Desenvolvimento, Transformação estrutural, Periférico.

\section{Abstract \\ The limits of the industry's contribution to development in the Lula and Dilma administrations: a new version of peripheral industrialism?}

This paper aims to analyze the limits of the contribution of Brazilian industry to development in two different moments: the cycle of relative growth between 2003-2010 and the deceleration and reversal between 2011-2015. For this, the structural decomposition methodology is used through the shift-share technique, in order to measure such contribution in three dimensions: (i) productivity, (ii) wages and average remuneration and (iii) sophistication of exports in relation to imports. The article relates to Wilson Cano's reflections considering three dimensions: (i) its understanding of development and underdevelopment as historical processes, (ii) the justification of the centrality of industrialization as an instrument to circumvent the reproduction of the structural heterogeneity characteristic of underdevelopment and (iii) the centrality of national development as a vector of such strategy. The paper suggests the consolidation of a pattern of structural organization of Brazilian industry that limits its capacity to contribute to development, independently of economic cycles. These limits would materialize in the incapacity to create a virtuous development cycle that fosters the reconfiguration of the productive structure. Finally, it is concluded that these limits are associated with the phenomenon that this paper suggests is interpreted as a new version of peripheral (and now regressive) industrialism.

Keywords: Cano, Wilson, 1937-2020, Industry, Development, Structural transformation, Peripheral.

JEL O14, O54, L16, F54.

\footnotetext{
${ }^{*}$ Artigo recebido em 16 de novembro de 2020 e aprovado em 8 de agosto de 2021.

${ }^{* *}$ Professor do Instituto de Economia da Universidade Estadual de Campinas (IE-Unicamp), Campinas, SP, Brasil. E-mail: diegues@unicamp.br. ORCID: http://orcid.org/0000-0002-4124-666X.
} 


\section{Introdução}

O objetivo deste artigo é analisar os limites da contribuição da indústria brasileira ao desenvolvimento entre 2003 e 2015. Para se compreender o caráter estrutural destes limites, será realizado um recorte temporal que buscará analisá-los em dois momentos qualitativamente distintos: o ciclo de aceleração do crescimento entre 2003 e 2010 e a desaceleração e reversão entre 2011 e 2015.

Neste intuito, o presente trabalho dialoga com as contribuições de Wilson Cano em três dimensões complementares, as quais estão presentes nas próximas seções. São elas: (i) sua compreensão do desenvolvimento e do subdesenvolvimento como processos históricos, (ii) a justificativa da centralidade da industrialização como instrumento para contornar a reprodução da heterogeneidade estrutural característica do subdesenvolvimento e (iii) a centralidade de um projeto de desenvolvimento nacional como vetor de tal estratégia (Cano, 2010).

Com relação à primeira dimensão, em aderência às contribuições de Cano, entende-se o desenvolvimento como

resultado de um longo processo de crescimento econômico, com elevado aumento da produtividade média, sem o qual o excedente não cresce o bastante para acelerar a taxa de investimento e diversificar a estrutura produtiva e do emprego. Esse processo intensifica a industrialização e urbanização para transformar de maneira progressista as estruturas sociais e políticas do país (Cano, 2014, p. 139).

Conforme destaca o autor, a transformação estrutural associada à industrialização se configura como elemento histórico essencial - porém não suficiente per se - para viabilizar as bases materiais deste processo, como mostram reflexões expressas em artigo publicado pelo Centro Internacional Celso Furtado de Políticas para o Desenvolvimento por meio da revista Cadernos do Desenvolvimento. Assim, ao analisar a relação entre (Des)Industrialização e (Sub)Desenvolvimento, Cano apresenta fundamentações históricas e teóricas que mostram que para que o desenvolvimento ocorra,

a industrialização tem de avançar e crescer mais que os outros setores, aumentar a produtividade, alterar sua estrutura - no sentido de implantar os compartimentos de bens de capital e intermediários, contribuindo, assim, para a diversificação da pauta exportadora e, se possível, para a melhoria das contas externas (Cano, 2014, p. 140).

Nesse sentido, conclui que "não há, na história, país algum que se desenvolveu, prescindindo de uma generalizada industrialização e de um forte e ativo papel do Estado Nacional" (Cano, 2014, p. 140). É exatamente a partir deste arcabouço que este artigo irá analisar os limites da contribuição da indústria ao desenvolvimento nos períodos Lula e Dilma.

Ainda em aderência às reflexões de Cano, a hipótese é a de que, dadas as configurações estruturais da indústria brasileira, os limites de sua contribuição ao desenvolvimento se estenderam durante todos os anos 2000, inclusive no breve período de elevado crescimento na primeira década deste século. Isso porque, após um longo período de permanente reação defensiva à concorrência internacional, a indústria brasileira teria reorganizado sua estratégia de concorrência e acumulação a partir do aprofundamento da integração importadora às cadeias globais de valor e da busca por 
competitividade na esfera doméstica a partir da redução de custos desvinculada do aumento do investimento, fato este que contribuiria decisivamente para a estagnação do crescimento da produtividade no período. Este padrão de organização, por sua vez, também estaria associado à incapacidade de se incrementar a sofisticação das exportações com vistas a reduzir a restrição externa ao crescimento. Por fim, faria com que a evolução da remuneração média real não apresentasse uma tendência de crescimento sustentável em médio prazo, dada a regressão estrutural da indústria, caracterizada pelo aumento da participação relativa de setores e atividades com menor produtividade e baixos níveis de remuneração.

A fim de se analisar os limites da contribuição da indústria ao desenvolvimento brasileiro, este artigo utiliza a metodologia de decomposição estrutural por meio da técnica de shif-share, tal qual expressa nos trabalhos de McMillan e Rodrik (2011); Unctad (2016) e Timmer e de Vries (2009). A mensuração desta contribuição será analisada em três dimensões: (i) produtividade, (ii) salários e remuneração média e (iii) sofisticação das exportações em relação às importações. A partir da análise dos componentes intrasetoriais e intersetoriais dinâmicos e estáticos, espera-se que um processo de desenvolvimento virtuoso esteja associado à reconfiguração da estrutura produtiva em direção a atividades que aumentem a produtividade, a remuneração média e o grau de sofisticação das exportações, tal qual sugere a literatura examinada na seção 2 .

Ao analisar o comportamento destes componentes tanto no período de relativa pujança nos governos Lula (2003 a 2010), quanto na desaceleração e posterior recessão nos governos Dilma (2011 a 2015) ${ }^{1}$, o artigo busca contornar uma limitação da literatura ao avançar para além das análises centralizadas apenas na dinâmica da desindustrialização e da especialização regressiva. Assim, são duas as principais contribuições pretendidas. A primeira consiste em mostrar empiricamente a incapacidade da indústria brasileira nos anos 2000 de engendrar um processo virtuoso de crescimento associado à transformação estrutural, independentemente da dinâmica dos mercados doméstico e internacional e do desempenho no que diz respeito à acumulação do capital alocado na esfera industrial. A segunda contribuição consiste em mensurar e analisar as especificidades de tais limitações segundo diferentes blocos setoriais: intensivos em escala, baseados em ciência e em recursos naturais, diferenciados e intensivos em trabalho, a partir de classificação internacionalmente comparável $^{2}$.

(1) Justifica-se a utilização do ano de 2015 como o último do período Dilma pelo fato deste ter sido o último ano completo de seu segundo mandato.

(2) Com base na classificação expressa em OECD (1987) a partir de Pavitt (1984), os setores intensivos em recursos naturais são (segundo códigos CNAE ao nível de 2 e 3 dígitos): 05 Extração de carvão mineral, 06 Extração de petróleo e gás natural, 07 Extração de minerais metálicos, 08 Extração de minerais não-metálicos, 09 Atividades de apoio à extração de minerais, 10 Fabricação de produtos alimentícios, 11 Fabricação de bebidas, 12 Fabricação de produtos do fumo, 15.1 Curtimentos e outras preparações de couro, 16 Fabricação de produtos de madeira, 17.1 Fabricação de celulose e outras pastas para a fabricação de papel, 19 Fabricação de coque, de produtos derivados do petróleo e de biocombustíveis e 23 Fabricação de produtos de minerais não-metálicos. Os setores intensivos em trabalho são: 13 Fabricação de produtos têxteis, 14 Confecção de artigos do vestuário e acessórios, 15.2 Fabricação de artigos para viagem e de artefatos diversos de couro, 15.3 Fabricação de calçados, 15.4 Fabricação de partes para calçados, de qualquer material, 25 Fabricação de produtos de metal, exceto máquinas e equipamentos, 31 Fabricação de móveis, 32.1 Fabricação de artigos de joalheria, bijuteria e semelhantes, 32.2 Fabricação de instrumentos musicais, 32.3 Fabricação de artefatos para pesca e esporte, 32.4 Fabricação de brinquedos e jogos recreativos e 32.9 Fabricação de produtos diversos. Os setores intensivos em escala são: 17.2 Fabricação de papel, cartolina e papel-cartão, 17.3 Fabricação de embalagens de papel, cartolina, papel-cartão e papelão ondulado, 17.4 Fabricação de produtos diversos de papel, cartolina, papel-cartão e papelão ondulado, 18 Impressão e reprodução de gravações, 20 Fabricação de produtos químicos, 22 Fabricação de produtos 
Para tal, o artigo estrutura-se em três seções, além da introdução e das considerações finais. Na seção 2 é apresentado um breve debate histórico e teórico para a compreensão da centralidade da contribuição da indústria para o processo de desenvolvimento. A seção 3 traz uma caracterização do desempenho industrial brasileiro nos períodos Lula e Dilma, com ênfase na relação entre regressão estrutural, especialização regressiva e dinâmica de acumulação. Já a seção 4 apresenta os resultados empíricos da relação entre decomposição estrutural e impactos em produtividade, remuneração média e sofisticação das exportações. Em seguida são apresentadas as considerações finais.

\section{A centralidade da contribuição da indústria para o desenvolvimento: aspectos históricos e teóricos}

A partir da interpretação de Furtado (1961) e em aderência às reflexões presentes em Cano (2010 e 2014) e brevemente citadas na seção anterior, este trabalho compreende o desenvolvimento como um processo no qual a geração de excedente e a acumulação ocorrem em paralelo à realização de investimento e incorporação do progresso técnico à dimensão produtiva, no sentido de fomentar a transformação estrutural da economia. Uma vez que os investimentos são importantes instrumentos de incorporação de progresso técnico nas atividades produtivas, a transformação estrutural está intrinsecamente relacionada à dinâmica de destruição criadora (Schumpeter, 1942). Como um dos principais resultados deste processo de desenvolvimento observar-se-ia a reconfiguração da estrutura produtiva, com o decorrente florescimento, a consolidação e o aumento da participação relativa na economia de atividades com maior produtividade, maiores níveis salariais e que viabilizem maior sofisticação das exportações. Assim, conforme destaca Rodrik (2007), "a principal característica do desenvolvimento é a mudança estrutural - o processo de redirecionar recursos de atividades tradicionais de baixa produtividade às modernas atividades de alta produtividade". Ainda segundo o autor, "tal fato está longe de ser um processo automático, e requer mais do que o pleno funcionamento do livre mercado. É responsabilidade da política industrial estimular investimentos (...) em novas atividades(...)" (tradução livre) (Rodrik, 2007, p. 7).

Neste sentido, como estratégia para fomentar a reconfiguração em direção a atividades de maior produtividade em países subdesenvolvidos, desde o nascimento da economia do desenvolvimento como uma disciplina autônoma nos primórdios do pós II Guerra Mundial, as interpretações de autores como Rosenstein-Rodan (1943); Lewis (1954); Rostow (1956); Gerschenkron (1973); Hirschman (1958) entre outros, destacam a centralidade da industrialização.

\footnotetext{
de borracha e de material plástico, 24 Metalurgia, 29 Fabricação de veículos automotores, reboques e carrocerias, 30.1 Construção de Embarcações, 30.3 Fabricação de veículos ferroviários, 30.5 Fabricação de veículos militares de combate e 30.9 Fabricação de equipamentos de transporte não especificados anteriormente. Os setores diferenciados são: 26.1 Fabricação de componentes eletrônicos, 26.3 Fabricação de equipamentos de comunicação, 26.4 Fabricação de aparelhos de recepção, reprodução, gravação e amplificação de áudio e vídeo, 26.6 Fabricação de aparelhos eletromédicos e eletroterapêuticos e equipamentos de irradiação, 26.7 Fabricação de equipamentos e instrumentos ópticos, fotográficos e cinematográficos, 26.8 Fabricação de mídias virgens, magnéticas e ópticas, 27.1 Fabricação de geradores, transformadores e motores elétricos, 27.2 Fabricação de pilhas, baterias e acumuladores elétricos, 27.4 Fabricação de lâmpadas e outros equipamentos de iluminação, 27.5 Fabricação de eletrodomésticos, 27.9 Fabricação de equipamentos e aparelhos elétricos não especificados anteriormente, 28 Fabricação de máquinas e equipamentos e 32.5 Fabricação de instrumentos e materiais para uso médico e odontológico e de artigos ópticos. Os setores baseados em ciência são: 21 Fabricação de produtos farmoquímicos e farmacêuticos, 26.2 Fabricação de equipamentos de informática e periféricos, 26.5 Fabricação de aparelhos e instrumentos de medida, teste e controle; cronômetros e relógios, 27.3 Fabricação de equipamentos para distribuição e controle de energia elétrica e 30.4 Fabricação de aeronaves.
} 
Apesar das interpretações destes autores se situarem num amplo espectro que se estende por fundamentações teóricas, orientações normativas e compreensões lógicas distintas dos determinantes dos processos de industrialização, parece haver uma preocupação transversal com a centralidade dos processos de geração de excedente e acumulação. Esta, por sua vez, se configuraria com uma elevada barreira aos processos de industrialização tardia que caracterizam os esforços de desenvolvimento dos países subdesenvolvidos (Gerschenkron, 1973).

A fim de contornar tais barreiras e incrementar o investimento doméstico, as interpretações apresentadas pelos autores descritos no parágrafo anterior sugerem diversas estratégias, como a associação ao capital externo (Rostow, 1956), atuação direta e sistemática do Estado (RosensteinRodan, 1943; Gerschenkron, 1973, e de alguma forma Hirschman, 1958), íntima associação entre capital bancário e industrial (Gerschenkron , 1973), e até incremento da capacidade de acumulação e de conseguinte investimento derivadas da concentração de renda associada à elevada taxa de exploração da mão de obra (Lewis, 1954). De maneira complementar a tais estratégias, com ênfases variáveis segundo as diversas interpretações, os autores também apresentam a importância do acoplamento ao dinamismo externo via inserção exportadora como fator catalisador da acumulação doméstica.

Apresentados os condicionantes à ativação do circuito lógico dos processos de transformações estruturais, autores como Kaldor (1966; 1967) e Prebisch (1949), entre outros, concentram seus esforços analíticos, com uma maior ênfase normativa, na compreensão das especificidades dos instrumentos catalisadores destes processos. É exatamente neste esforço que destacam a posição hierarquicamente superior da industrialização como vetor do desenvolvimento e como condição sine qua nom para tal.

Na leitura de Prebish (1949), e em grande parte nas demais contribuições cepalinas, tal orientação normativa é justificada pelo fato da inserção periférica na divisão internacional do trabalho como ofertante de commodities e demandante de manufaturados limitar o investimento catalisador de transformações estruturais industrializantes. Isso porque, por meio da deterioração dos termos de troca observar-se-ia a permanente transferência dos frutos do progresso técnico da periferia para o centro, o que inviabilizaria o processo de geração, acumulação e até controle do excedente necessário para viabilizar tais transformações e reduzir a heterogeneidade estrutural característica da periferia (Pinto, 1970).

Neste mesmo sentido, e ao contrário do que sugerem as leituras fundamentadas na ideia da especialização fundamentada nas vantagens comparativas ricardianas, Kaldor $(1966,1967)$, procura mostrar que as características da estrutura produtiva são elementos condicionantes fundamentais das trajetórias possíveis de desenvolvimento. Assim, por meio daquilo que posteriormente seria denominado por Thirlwall (1983) como Leis de Kaldor, mostra de maneira empírica que a industrialização se configura como elemento central para o desenvolvimento, uma vez que apresenta grande capacidade de alavancar o crescimento do PIB, de difundir inter e intrasetorialmente o progresso técnico e de reduzir o estado de permanente estrangulamento externo das economias periféricas dadas as diferenças de elasticidade renda da demanda entre suas exportações e importações. 
A partir deste mesmo recorte, Hirschmann (1958) também identifica na transversalidade das atividades industriais o vetor para o incremento das decisões de investimento associadas a transformações estruturais. Estas seriam viabilizadas pelos efeitos derivados da complementaridade entre os diversos setores produtivos, o espraiamento do dinamismo via encadeamentos e impulsos a decisões de efetivação de investimentos viabilizados pelos desequilíbrios setoriais intrínsecos ao processo de transformação estrutural.

Entretanto, como já alertam trabalhos seminais como Report on Manufactures de Alexander Hamilton (1791) e Sistema Nacional de Economia Política de Friedrich List (1841), tais processos não se configuram como desdobramentos naturais da constituição das forças produtivas, ao contrário do que pode sugerir a leitura teleológica das interpretações etapistas do desenvolvimento como presente em Rostow (1956).

A partir de uma leitura histórica e teórica, Chang (1994; 2004) enfatiza a centralidade de políticas de desenvolvimento como instrumentos a fim de se viabilizar trajetórias de industrialização em suas diversas materializações, inclusive nos processos originários, atrasados e tardios daqueles que o autor denomina de PADs (países atualmente desenvolvidos). Neste contexto, dado o fato do processo de desenvolvimento - em sua dimensão produtiva - se materializar por meio de constantes mudanças estruturais, rupturas e a criação permanente de desequilíbrios setoriais, a reconfiguração permanente das estratégias de políticas de desenvolvimento é elemento central para a viabilização dos esforços de catching up produtivo e tecnológico. Tais desafios, por sua vez, se colocam ainda com mais ênfase quando os esforços em questão são empreendidos por países subdesenvolvidos. Inúmeras são as justificativas para tal afirmação, das quais se destacam (i) a necessidade de contornar as limitações impostas pela substancial heterogeneidade estrutural na dimensão produtiva doméstica e internacional - face aos elevados diferenciais de produtividade em relação aos PADs e (ii) a capacidade de, apesar da dependência tecnológica, financeira, política e principalmente no que diz respeito à formulação da agenda de políticas públicas, construir uma correlação de forças políticas que permita a formulação de uma estratégia de desenvolvimento que tenha como alicerce o comando, a apropriação e o direcionamento do excedente em alinhamento a uma estratégia ampla de desenvolvimento não apenas no sentido tecnicista, mas no sentido de se ampliar a autonomia das forças produtivas nacionais (Chang, 1994).

Em síntese, conforme lembra Cano (2012), o desenvolvimento está associado historicamente ao avanço da industrialização generalizada amparada no Estado Nacional. Para tal, ainda reforça o autor, é necessário fomentar a consolidação da empresa nacional, conforme mostraram as estratégias de desenvolvimento de Alemanha, Japão, Coréia do Sul (e atualmente China). Segundo Cano,

Tais países tinham não só circunstâncias internacionais extremamente favoráveis para que suas empresas ficassem mais fortes e agressivas e fossem vitoriosas no cenário internacional, como tinham políticas de Estado voltadas para isso, ou seja, protecionistas, direcionadas para a industrialização, financiadoras da atividade industrial. A Coreia do Sul chegou a proibir o consumo interno de televisão colorida, direcionando sua produção para exportar. Houve a prática de políticas macroeconômicas internas e políticas industriais, além de circunstâncias internacionais, que permitiram que suas grandes empresas crescessem e alcançassem um desempenho extraordinário no cenário internacional. Houve, acima de tudo, um Estado Nacional e, não raro, um estadista que soube conduzir esse processo (Cano, 2014, p. 170-171). 
É a partir deste arcabouço que este artigo procura analisar a relação entre indústria e desenvolvimento, dada a centralidade que tais trabalhos clássicos atribuem ao processo de transformação estrutural como elemento constitutivo do processo lógico do desenvolvimento econômico em sua dimensão produtiva.

Compreende-se que as intensas transformações desde a transição do paradigma fordista/chandleriano para o da microeletrônica, a gestação das cadeias globais de valor e os atuais esforços para a constituição do que tem se convencionado denominar Indústria 4.0, trazem novos elementos para se analisar a dinâmica concorrencial, inovativa e de acumulação da indústria em muitas dimensões (Brun; Gereffi; Zhan, 2019). Exigem, inclusive, conforme Andreoni e Chang (2019); O’Sullivan et al. (2013) e Diegues e Roselino, (2019), a reconfiguração conceitual, normativa e institucional das políticas industriais e de desenvolvimento.

Entretanto, a despeito destas inúmeras transformações, entende-se que a relação lógica entre indústria e desenvolvimento, compreendida como a da capacidade da transformação estrutural impactar positivamente, nas dimensões intra e intersetorial (i) o incremento da produtividade, (ii) o aumento da remuneração média e (iii) o aumento do grau de sofisticação das exportações em comparação ao grau de sofisticação das importações, persiste como elemento constitutivo do desenvolvimento produtivo (McMillan; Rodrik, 2011; UNCTAD, 2016; Timmer; de Vries, 2009). Em outras palavras, apesar das transformações na forma de materialização da indústria desde os anos 1970 (Berger, 2013), o circuito lógico de sua contribuição ao desenvolvimento remete às definições conceituais apresentadas no arcabouço teórico analisado nesta seção (Andreoni; Gregory, 2013).

\section{A consolidação de uma nova versão do industrialismo periférico? A dinâmica de organização e acumulação da indústria brasileira nos períodos Lula e Dilma}

O debate sobre as transformações na estrutura produtiva brasileira nos anos 2000 tem centralizado suas análises na compreensão dos determinantes da desindustrialização. De maneira geral, as interpretações que têm como arcabouço o mesmo referencial teórico apresentado na seção anterior entendem que este processo deriva de um esgotamento da dinâmica de industrialização por substituição de importações em um cenário de crise do desenvolvimentismo (Coutinho, 1997; Carneiro, 2002).

Segundo a contribuição de Cano publicada nesta mesma Economia e Sociedade, em edição especial de dezembro de 2012, o processo de desindustrialização vigente até aquele ano poderia ser entendido a partir da interação de cinco principais fatores associados intimamente à crise do desenvolvimentismo:

1. Uma das causas principais tem sido a política cambial prevalecente, instaurada a partir do Plano Real. O resultado (...) foi a crescente perda de competitividade internacional da indústria nacional perante outros países;

2. Outra razão resulta da abertura desregrada pela qual o Brasil passou e passa desde 1989;

3. Terceira razão: a taxa de juros elevada do país;

4. (Quarta razão) (...) a guinada de IDE predominantemente americano e asiático para a China em busca de trabalho barato, câmbio desvalorizado e alta competitividade. Por essa razão, ele se 
mudou, em grande parte, para a China a fim de produzir mais barato, abandonando ou diminuindo sua presença em antigas áreas onde havia tido grande expressão (como no Brasil);

5. A quinta razão que deixa os economistas ainda mais preocupados é que de 2007 para cá, a economia mundial desacelerou (o que fez com que países como EUA e especialmente a China desenvolvessem) políticas agressivas no mercado internacional de produtos manufaturados, obtendo taxas elevadas de crescimento dessas exportações e recuperando parte do terreno perdido (Cano, 2012, p. 834-835).

A partir desta intepretação, o desdobramento amplo da crise do desenvolvimentismo implicou em um vasto conjunto de medidas que se materializaram nas abruptas e intensas aberturas comercial e financeira, e culminaram em um cenário com fortes oscilações nos preços macroeconômicos, caracterizado desde então pela persistente apreciação do real, pela vigência de taxas de juros elevadas e pelo baixo investimento público (tanto na esfera empresarial quanto em infraestrutura e na dimensão social). Ao ampliarem o escopo deste debate, Hiratuka e Sarti (2015) destacam os impactos das transformações do sistema produtivo global na estrutura produtiva brasileira. Para tal, enfatizam a reconfiguração das cadeias globais de valor com o deslocamento das atividades produtivas em direção à Ásia - e o conseguinte fenômeno de 'chinalização industrial' (Sarti; Hiratuka, 2017) - e o acirramento das pressões competitivas internacionais.

Outra corrente expoente a partir do mesmo referencial teórico deste trabalho é aquela que analisa as transformações na estrutura produtiva brasileira a partir da ótica da Doença Holandesa, cujos principais expoentes são os trabalhos de Bresser-Pereira (2008, 2010); Bresser-Pereira e Marconi (2010); Oreiro e Feijó (2010) e Palma (2005). Sinteticamente, o fenômeno da Doença Holandesa explica a redução do papel da indústria no desenvolvimento econômico como resultado da apreciação das moedas locais decorrente de um desempenho exportador pujante nos setores de commodities e do ingresso de capitais especulativos incentivados principalmente pelos diferenciais de juros internos e externos, o que aumenta a lucratividade e a atratividade relativa desses setores frente às atividades manufatureiras.

A interpretação deste trabalho, por sua vez, defende que as transformações na estrutura produtiva brasileira nos anos 2000 deve ser entendida a partir de dois recortes distintos. O primeiro deles, conforme Diegues e Rossi (2017), compreende o período dos governos Lula (2003 e 2010) e é denominado pelos autores como de vigência de uma "Doença Brasileira". Já no segundo período, entre 2011 e 2015, apesar de importantes transformações na política industrial capitaneada nos governos Dilma, também se verifica a continuidade da tendência de desindustrialização e de redução da capacidade de contribuição da indústria para o desenvolvimento (conforme será mostrado na seção 4).

O período caracterizado como de Doença Brasileira (2003 a 2010, nos governos Lula) foi marcado pela coexistência entre especialização regressiva e ampliação da acumulação do capital alocado na esfera industrial. Conforme Diegues e Rossi (2017, p. 10), tal acumulação estaria associada à emergência de estratégias crescentemente desvinculadas do desempenho estritamente produtivo, "e seria baseada no seguinte tripé: 
Os limites da contribuição da indústria ao desenvolvimento nos períodos Lula e Dilma: uma nova versão do industrialismo periférico?

(i) reorganização das unidades produtivas locais, adequando-as aos novos condicionantes competitivos das redes globais de produção e viabilizando assim a integração essencialmente importadora nessas redes;

(ii) aumento do mercado interno, fomentado pela distribuição de renda, aumento da massa salarial, do emprego e do crédito e

(iii) acoplamento do parque produtivo doméstico ao mercado internacional como grande ofertante de produtos baseados em recursos naturais."

Assim, em um cenário de Doença Brasileira, o dinamismo produtivo relativamente baixo e o desadensamento entre 2003 e 2010 seriam explicados por um novo padrão de organização e acumulação do setor industrial local. Este padrão seria caracterizado pela redução do conteúdo local e pelo crescimento exponencial da importação de produtos finais, partes, peças e componentes a partir da integração importadora nas cadeias produtivas globais.

Como reflexos da Doença Brasileira, observou-se uma tendência generalizada de desindustrialização em paralelo à concentração crescente do parque manufatureiro em setores intensivos em recursos naturais, como mostram os trabalhos de Morceiro (2012, 2018), Bresser (2008, 2010, 2013), entre outros. Adicionalmente, a soma de desadensamento produtivo com aumento do coeficiente de penetração levaram a uma redução e/ou estagnação da intensidade de capital por trabalhador (Gráfico 1), com destaque para os setores intensivos em escala. A exceção significativa a este fenômeno restringe-se aos setores intensivos em recursos naturais, o qual foi responsável por $76 \%$ do crescimento do ativo industrial brasileiro entre 2003 e 2010.

Gráfico 1

Taxas de Crescimento da Razão Ativo Total / PO, 2003 a 2010, segundo setores agrupados por tipos de tecnologia

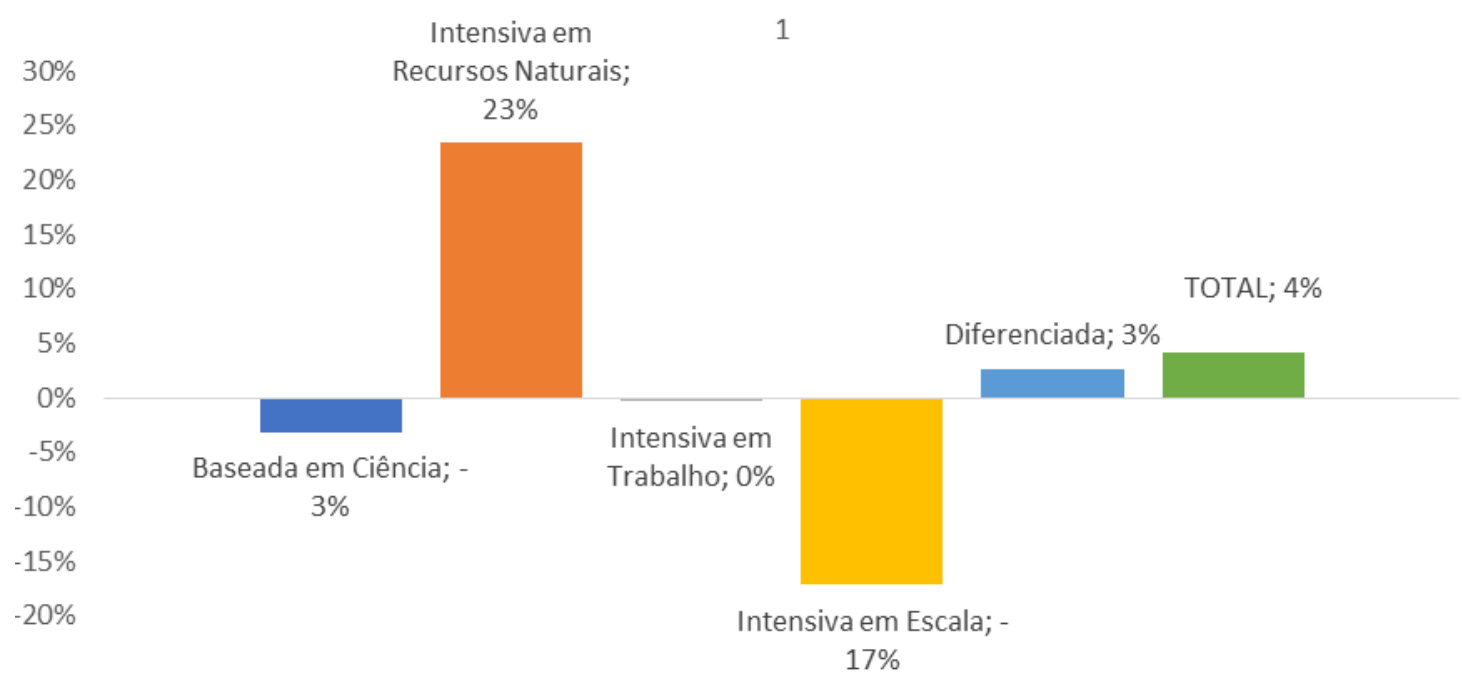

Fonte: Elaboração própria a partir de PIA - IBGE - Vários Anos. Classificação baseada em OECD (2005), a partir de Pavitt (1984). Dados deflacionados segundo IPA -FGV. Empresas com 30 ou mais pessoas ocupadas. 
A desvinculação crescente da acumulação da dimensão produtiva, com o aumento da dependência da indústria local de uma integração importadora às cadeias globais, por sua vez, foi potencializada pela tendência praticamente contínua de apreciação da moeda local entre 2003 e 2010, dados seus impactos nos custos dos componentes importados e também nos custos financeiros derivados do endividamento externo das grandes empresas industriais locais (Gráfico 2).

Gráfico 2

Taxas de Crescimento Ativo Total e Receita Total menos Custo Total, segundo setores agrupados por tipos de tecnologia, 2003 a 2010

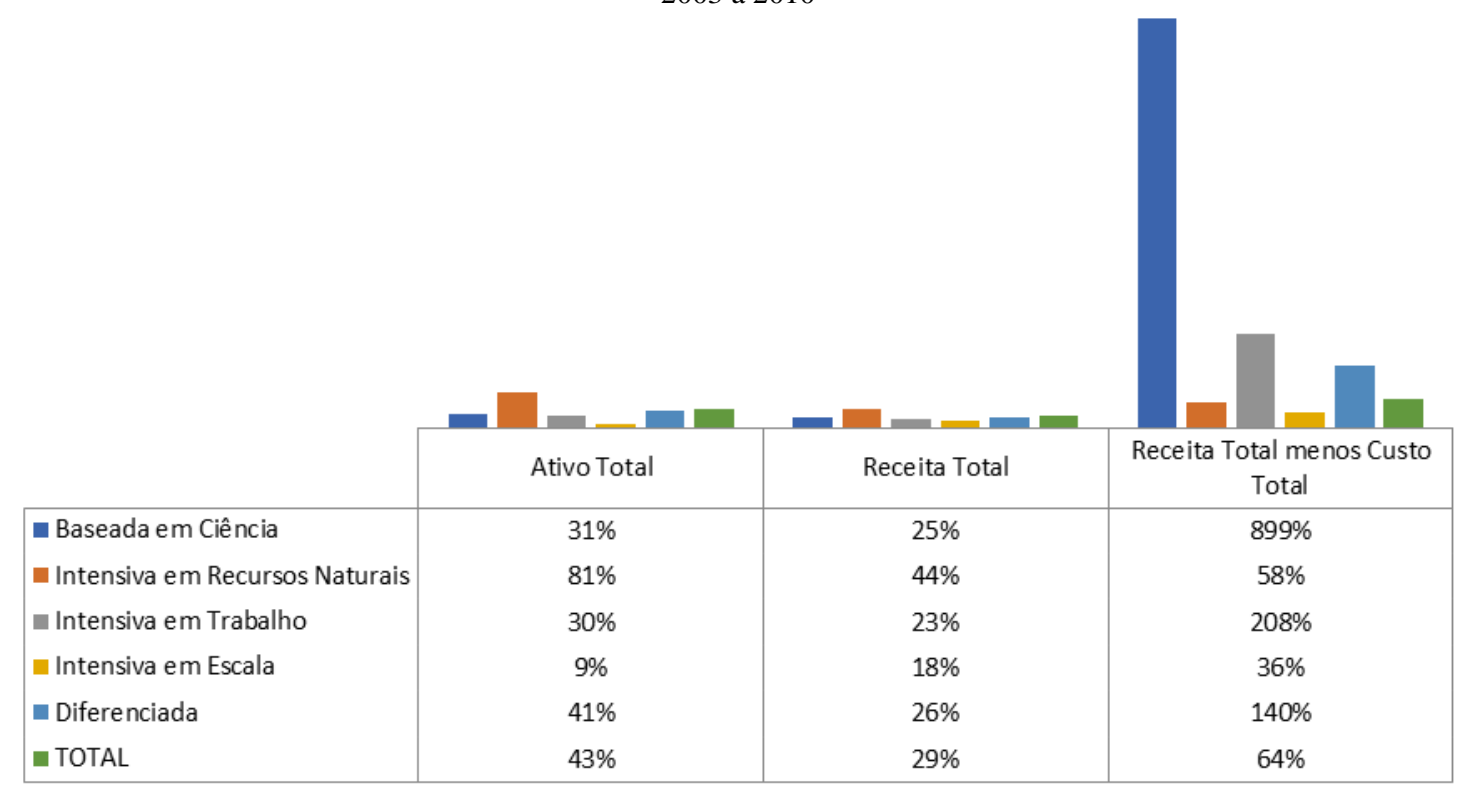

Fonte: Elaboração própria a partir de PIA - IBGE - Vários Anos. Classificação baseada em OECD (1987) a partir de Pavitt (1984). Dados deflacionados segundo IPA - FGV. Empresas com 30 ou mais pessoas ocupadas.

Assim, ao contrário do que sugerem as interpretações convencionais sobre os determinantes da acumulação na esfera industrial, observou-se no período um aumento da massa da taxa de lucros da indústria. Conforme apontam Diegues e Rossi (2017, p. 22), verifica-se que, para a indústria brasileira, a média do indicador expresso pela divisão do lucro pela receita aumentou de $2 \%$ no período 1996-2002 para 9\% entre 2003 e 2010 (em aderência às conclusões de Rocha, 2015 e Hiratuka; Rocha, 2015). Em seguida, os autores concluem que "o baixo dinamismo produtivo da indústria local mesmo em um cenário de crescimento econômico até 2010 foi, na verdade, o sintoma de um padrão de organização e acumulação exitoso" que "lhe permitiu se libertar ainda que parcialmente das amarras da atividade produtiva na primeira década de 2000 ".

No entanto, não se considera exagerado reiterar novamente que as características deste processo se referem fundamentalmente ao período 2003 a 2010. Ou seja, insere-se majoritariamente no primeiro período analisado por este trabalho: aquele de relativa pujança dos governos Lula. Conforme fora sustentado anteriormente, a combinação entre desindustrialização e aumento da capacidade de acumulação só se mostrou viável devido à vigência de elementos que se materializam no tripé (i) reorganização das unidades produtivas locais, com aumento da integração importadora 
nas redes globais de produção, (ii) pujança do mercado interno e (iii) acoplamento do parque produtivo doméstico ao mercado internacional como grande ofertante de produtos intensivos em recursos naturais.

De maneira geral, este trabalho compreende que a integração importadora nas redes globais apresenta um caráter estrutural, pois emerge como resultado da combinação entre o esgotamento do modelo de industrialização brasileiro por substituição de importações em paralelo à reorganização empresarial e dos sistemas produtivos globais em um cenário de "chinalização industrial" (Sarti; Hiratuka, 2017). Os demais fatores, por sua vez, apresentam caráter conjuntural. Assim, na medida em que se observou uma forte reversão do crescimento do mercado interno na segunda década dos anos 2000, era de se esperar que em face a uma retração da demanda, a indústria brasileira encontrasse dificuldades para manter o mesmo patamar da taxa de lucro vigente no período anterior. Essa mesma constatação também se aplica quando se analisa o impacto do esgotamento do boom de preços das commodities na dinâmica de acumulação das empresas locais exportadoras de produtos intensivos em recursos naturais.

Neste cenário, dada a reconfiguração dos elementos conjunturais do tripé que viabilizam a coexistência de movimentos de desindustrialização em paralelo ao aumento da acumulação da indústria brasileira, observam-se evidências de esgotamento de uma parcela deste processo (o aumento da acumulação) a partir do segundo período analisado por este artigo: a desaceleração e posterior recessão econômica nos Governos Dilma.

Uma vez que a integração importadora do parque produtivo local às redes globais de produção apresenta componentes de natureza estrutural, a reversão do movimento conjuntural de apreciação da moeda local a partir do primeiro governo Dilma tenderia a contribuir negativamente para a acumulação do capital alocado na esfera industrial, ao menos no curto prazo. Tal contribuição negativa decorreria do aumento dos custos dos insumos e produtos importados e seria potencializado pelo aumento dos volumes em moeda local necessários para a rolagem e amortização das dívidas contraídas por empresas locais no mercado internacional. A dimensão potencial deste impacto pode ser percebida quando se verifica que em 2014, por exemplo, o mercado internacional representava 54,3\% no total de financiamentos das companhias abertas (exceto Vale e Petrobrás) da indústria de transformação (CEMEC-IBMEC, 2014). Conforme lembram Gomes, Novais e Rocha (2016, p. 16), "isto significa dizer que o patamar da taxa de câmbio não possui efeito unívoco em relação aos estímulos à indústria, e que no equacionamento do crescimento, o peso das despesas financeiras pode ter um papel, no curto-prazo, fundamental (..)".

Adicionalmente, o desaquecimento do mercado consumidor doméstico e a posterior retração do mesmo, bem como o esgotamento do boom internacional de preços das commodities também tenderiam a contribuir negativamente para a dinâmica de acumulação de setores industriais ligados ao mercado doméstico e à exportação de recursos naturais.

Neste cenário seria esperada, a partir da segunda década de 2000, uma deterioração dos indicadores de lucratividade e rentabilidade das empresas industriais. Potencializados pelos impactos negativos da depreciação da moeda local na evolução do estoque - bem como na rolagem e amortização - de dívidas denominadas em dólares, estes impactos contribuiriam para a deterioração da capacidade de acumulação industrial no período. 
Conforme destacam CEMEC-IBMEC (2014; 2015), esta deterioração da rentabilidade é entendida como um dos principais responsáveis pelo baixo dinamismo do investimento brasileiro pós 2010. A título de ilustração, neste mesmo ano, o retorno sobre o capital próprio das companhias abertas e das maiores empresas fechadas (Petrobrás, Eletrobrás e Vale), atingiu a marca de 7,2\%, depois de se situar em patamares sempre acima de $20 \%$ entre 2005 e 2007 e manter-se em $17 \%$ em 2010. Apesar destes indicadores de retorno sobre o capital serem apresentados pelo relatório de maneira agregada - o mesmo enfatiza que "o setor que apresenta maior redução de lucros é o industrial" (p. 11).

A tese subjacente à afirmação anterior é a de que tal deterioração na capacidade de acumulação seria a principal responsável pela queda do investimento produtivo na economia doméstica. Em última instância, essa redução do investimento explicaria a incapacidade de se engendrar um processo de transformação estrutural associado ao aumento da produtividade e ao crescimento da renda doméstica.

Entretanto, apesar da deterioração dos indicadores de rentabilidade implicar em um menor potencial de acumulação a partir dos Governos Dilma, a própria organização do sistema produtivo brasileiro gestada desde o início dos anos 2000 traz elementos para questionar a validade da ideia expressa no parágrafo anterior. Isso porque, dada essa organização, o aumento da acumulação não estaria necessariamente vinculado ao aumento do investimento produtivo. Ao contrário disso, conforme se demonstrou ao analisar o período de 2003 a 2010, as características do padrão de inserção internacional do parque produtivo brasileiro permitem que, em um cenário de aquecimento da demanda interna e externa, a acumulação prescinda - ainda que parcialmente - da realização de parcelas substanciais do processo produtivo em solo nacional e, consequentemente, da necessidade de realização de substanciais investimentos produtivos.

Entretanto, a coexistência de desindustrialização e crescimento da taxa acumulação esgotase a partir da segunda década dos anos 2000. Tal fato decorre da reorganização do tripé que sustentava tal modelo de organização da indústria doméstica. No que diz respeito aos impulsos de demanda observa-se:

(i) a reversão do ciclo virtuoso de crescimento do mercado interno, fomentado pela distribuição de renda, aumento da massa salarial, do emprego formal e do crédito;

(ii) o rebaixamento do patamar de crescimento da economia chinesa (para o "novo normal") e a redução do ritmo de crescimento da economia mundial a partir da segunda fase da crise de 2008 apresentam impactos importantes no volume (no que diz respeito a preço e quantidade) das exportações brasileiras de commodities;

(iii) a reversão da tendência de apreciação da moeda local apresenta impactos negativos de curto prazo importantes na dinâmica de acumulação da indústria local. Isso porque dada a já consolidada inserção importadora do parque produtivo doméstico nas cadeias globais, tal medida deteriora a rentabilidade em diversas cadeias produtivas, principalmente aquelas mais dependentes de partes, peças, componentes e até produtos finais importados. Adicionalmente, a desvalorização da moeda local também significa custos financeiros crescentes incidentes sobre o estoque de 
dívidas denominado em dólar, o qual aumentou de maneira sólida sua participação no financiamento do capital industrial brasileiro no período Lula.

A conjugação destes três elementos de natureza conjuntural, dada a maneira de organização estrutural da indústria brasileira, ocasionou uma rápida redução de sua taxa de lucro. Como pode ser visto a partir dos dados da PIA-IBGE, que a razão entre lucro total e ativo na indústria de transformação e extrativa representava 6,1\% em 2011 e -2,8\% em 2015 (Gráfico 3).

Gráfico 3

Lucro Total dividido por Ativo, segundo tipos de tecnologia, de 2011 a 2015 - Em \%

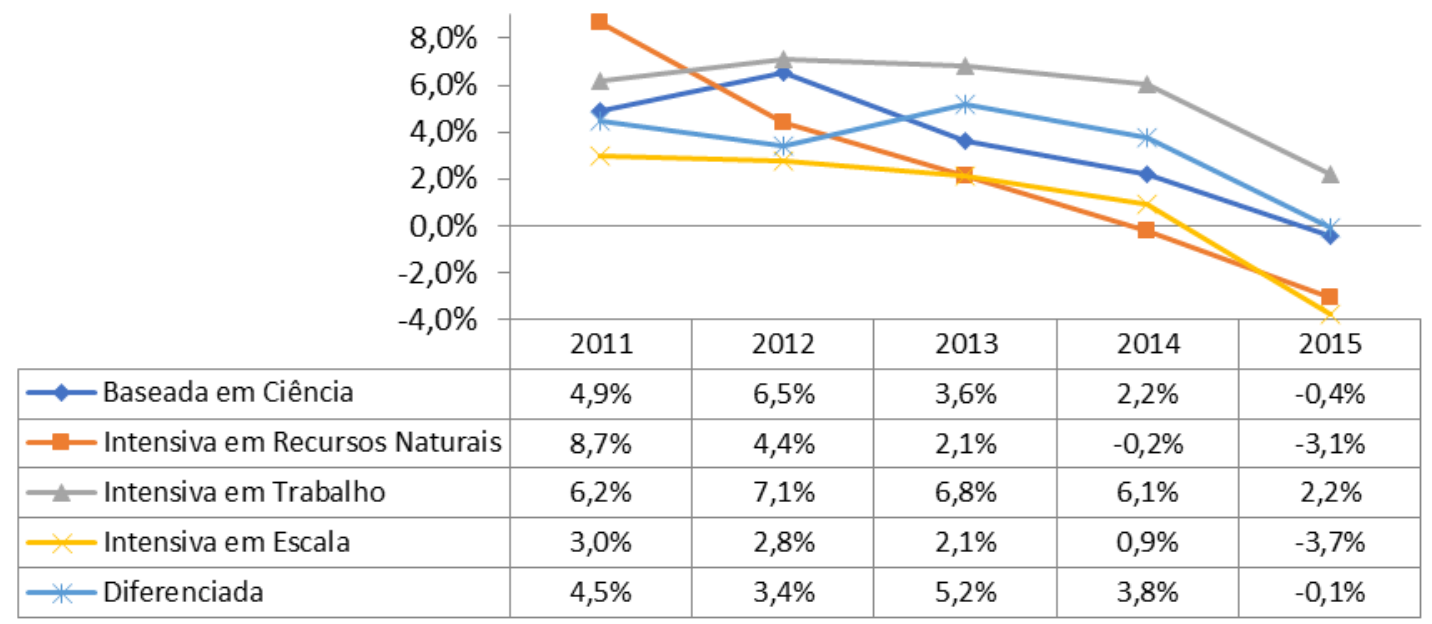

Fonte: Elaboração própria a partir de PIA - IBGE - Vários Anos. Classificação baseada em OECD (1987) a partir de Pavitt (1984). Dados deflacionados segundo IPA - FGV. Empresas com 30 ou mais pessoas ocupadas.

Em paralelo, a tendência de desindustrialização aprofundou-se a partir de 2011, com a manutenção das características estruturais apresentadas na década anterior: concentração crescente da importância relativa dos setores intensivos em recursos naturais (no que diz respeito ao valor da transformação industrial, emprego, investimento e superávit comercial) e movimento de transformação estrutural regressiva (Morceiro, 2018). Como resultado da acentuação deste movimento observa-se a dificuldade da indústria brasileira em engendrar uma dinâmica virtuosa que associe acumulação e investimento baseado em incorporação de tecnologia e inovação, com vistas a impulsionar atividades complexas e assim incrementar o nível de produtividade doméstica.

A despeito dos impactos conjunturais na lucratividade, a similaridade na dinâmica estrutural da indústria nos períodos Lula quanto Dilma traz elementos importantes que permitem sugerir que cada vez mais parece estar consolidada na estrutura produtiva doméstica uma nova versão do industrialismo periférico (e agora regressivo), com baixa capacidade de contribuição da indústria ao desenvolvimento (conforme será demonstrado empiricamente na seção 3). São dois os elementos que permitem compreender esta configuração como uma nova variação de um padrão que é constituinte da industrialização periférica brasileira. 
Primeiro, o fato de que, ao contrário do que se observou historicamente na economia brasileira, este padrão tem viabilizado a sustentação de sua acumulação a partir de uma estratégia que contraria o corolário normativo do desenvolvimento, o qual associa a industrialização à diversificação setorial e à transformação estrutural em direção ao upgrading técnico e produtivo. Assim, a indústria brasileira parece ter reagido - em termos estruturais - de maneira relativamente exitosa às transformações internacionais oriundas da liberalização financeira e comercial, bem como do surgimento das cadeias globais de valor, e engendrado uma estrutura ainda mais dependente das importações (tanto de bens intermediários quanto finais), do capital e da tecnologia externos. Ou seja, ao contrário do que sugeriria o industrialismo característico do desenvolvimentismo, a liberalização comercial e financeira se configurou como um instrumento para viabilizar a emergência de uma dinâmica de produção e acumulação no mínimo razoavelmente frutífera do parque produtivo periférico brasileiro. Tal dinâmica, ao libertar ainda que parcialmente a indústria brasileira das restrições impostas pela lógica produtivista, faz com que haja a possibilidade de coexistência entre sustentabilidade na dimensão da acumulação e aprofundamento do caráter regressivo da transformação estrutural. Este fato, por sua vez, também se reveste em uma característica específica do período entre 2003 e 2015 quando analisado em perspectiva histórica, dado que a transformação estrutural com o aumento do grau de diversificação no período desenvolvimentista foi a alavanca do dinamismo industrial brasileiro.

Segundo, o fato de que apesar da complementaridade à estrutura produtiva internacional ser uma diretriz do industrialismo periférico, esta ocorre de maneira essencialmente distinta a partir da formação das cadeias globais de valor - tanto no Brasil quanto em outras economias periféricas. Isso porque nestas cadeias não se observa a coexistência e a coincidência territorial entre a produção, a geração e a apropriação do valor. Assim, a complementaridade periférica assume um caráter distinto, dado que se dá não em termos setoriais ou de produtos, como tradicionalmente ocorreu no período desenvolvimentista, mas sim em termos das atividades realizadas domesticamente, as quais tendem a se concentrar em etapas menos nobres e com reduzida capacidade de agregação de valor na denominada 'curva sorriso'. Em uma abordagem semelhante, Cano (2012) sugere que

a guinada de IDE predominantemente americano e asiático para a China em busca de trabalho barato, câmbio desvalorizado e alta competitividade (trouxe) nocivos efeitos internos (à economia brasileira) (...) (uma vez que) afetaram profundamente os investimentos produtivos do setor, tornando-os de caráter mais específico, oportunistas e atomizados (Cano, p. 835-836).

Ainda em aderência à nova configuração da complementariedade com relação ao capital internacional tal qual sugerida por este trabalho, o comportamento do IDE

mostra dados inequívocos (sobre a redução do papel do IDE em fomentar uma base manufatureira doméstica): na década de 1980, a participação da indústria de transformação no IDE total girava em torno de $75 \%$; essa cifra cai para cerca de $60 \%$ na de 1990 e flutua entre $30 \%$ e $40 \%$ a partir de 2001. Ao mesmo tempo, a participação dos serviços sobe e, com eles, a das atividades financeiras (Cano, p. 835).

Em síntese, dado o fato de a produção nestas cadeias se organizar a partir de uma lógica fragmentada / modularizada, sua coexistência em paralelo à acentuação da liberalização financeira e comercial instrumentalizou a consolidação de uma nova dinâmica de produção e acumulação na 
indústria brasileira, incapaz de fomentar a transformação estrutural e a diversificação, independentemente do ciclo econômico doméstico. Essa dinâmica, ao contrário do que sugeririam as interpretações baseadas no arcabouço teórico que remonta às explicações clássicas e estruturalistas sobre o processo de industrialização, se beneficiaria estrategicamente do avanço da liberalização, uma vez que estaria crescentemente desvinculada da dinâmica produtivista característica do período desenvolvimentista.

Cumpre destacar que a dinâmica de produção, concorrência e acumulação característica dessa nova variação do industrialismo periférico é gestada em três períodos. Inicialmente as transformações na estrutura produtiva mundial no último quartel do século XX viabilizam as condições técnicas e financeiras para este processo. Na dimensão interna, a crise do desenvolvimentismo molda a reação da indústria brasileira a estes condicionantes. $\mathrm{O}$ segundo grande período de amadurecimento deste padrão ocorre na primeira década dos anos 2000, em decorrência da combinação de características que culminaram na coexistência de desindustrialização / especialização regressiva e incremento da acumulação do capital alocado na esfera industrial. Já o terceiro período, a partir dos governos Dilma, é marcado pela consolidação deste movimento, potencializado pela reversão cíclica e pela estratégia de enfrentamento a esta reversão baseada em uma compreensão incompleta do diagnóstico dos fatores que afetavam a dinâmica competitiva da indústria brasileira, conforme apontam Carneiro (2018), Mello \& Rossi, (2018) e Carvalho, (2018).

Assim, essa nova versão do industrialismo periférico (e agora regressivo) seria caracterizada pela:

(i) permanente estratégia defensiva por parte dos agentes industriais locais, na qual a busca pela competitividade não ocorre em paralelo à transformação estrutural virtuosa, com aumento da complexidade do processo produtivo e conseguinte aumento da produtividade. Ao contrário, tal busca se sustenta em estratégias regressivas baseadas em pressões permanentes para reduções de custos produtivos. A tais estratégias, características de todo o período em análise, são agregadas durante o período Dilma pressões adicionais para a ampliação do processo de redução defensiva de custos em outras esferas. Parcialmente vitoriosas desde então (e aprofundadas nos governos seguintes), essas pressões se materializam em medidas como a desoneração da folha de trabalho por meio da redução das contribuições previdenciárias e a contenção dos preços de tarifas públicas. Vale ressaltar ainda que o aprofundamento das pressões para a compressão destes custos produtivos deve ser compreendido em um cenário de espaço limitado para utilização do instrumento por excelência de incremento da competitividade em estratégias industrializantes - a vigência de uma taxa de câmbio relativamente desvalorizada. Isso porque a desvalorização estaria associada a efeitos negativos de curto prazo na acumulação local, dada a reconfiguração da estrutura produtiva em direção a uma integração essencialmente importadora nas redes produtivas globais;

(ii) nova forma de complementaridade ao capital produtivo internacional, possibilitada pela reorganização das atividades manufatureiras em formato do que se convencionou denominar de 'curva sorriso', na qual se observa um aumento da participação do parque produtivo doméstico em atividades vinculadas à representação deste (comercial, financeira e de marketing), à maquila $\mathrm{e}$ tropicalização de produtos importados; 
(iii) busca pelo incremento da competitividade e potencialização da acumulação via desoneração tributária. Apesar de fenômeno já estar presente parcialmente no segundo governo Lula (como medida de reação à crise de 2008), também se acentua no período Dilma dada a intensificação das pressões para uma nova escalada da redução de custos industriais como forma de enfrentamento à reversão do ciclo de crescimento doméstico;

(iv) tendência de concentração em setores historicamente caracterizados por apresentarem vantagens comparativas associadas à extração e processamento de recursos naturais, bem como em alguns setores que exigem altas escalas mínimas de eficiência e nos quais a existência de um mercado interno relevante é fundamental - como o setor petroleiro, indústria pesada e automobilística. Essa concentração se manifestaria tanto em indicadores influenciados diretamente pela dinâmica de acumulação (como massa de lucros, de receita e investimento) quanto naqueles vinculados à dimensão produtiva (como valor da transformação industrial, emprego e exportações).

Deste modo, ainda em aderência às constatações feitas em Carneiro (2018), Mello e Rossi, (2018) e Carvalho, (2018), afirma-se que a busca pela retomada da centralidade da indústria na estratégia de desenvolvimento brasileira, em um cenário de acirramento da concorrência global e de consolidação da China como a nova 'Workshop of the World', baseou-se em um diagnóstico que não compreendeu as transformações no padrão de organização e de acumulação da indústria local forjadas nos anos 2000. É exatamente por este motivo que o industrialismo do governo Dilma, ao se fundamentar em medidas que circunscrevam os desafios à estrutura produtiva brasileira a medidas relativas a uma agenda de incremento da competitividade via redução de custos mostrou sua patente insuficiência. Em outras palavras, a tese de que o 'enfrentamento do custo Brasil' traria consigo aumento da competitividade e conseguinte retomada do dinamismo e do investimento não se sustentou. Adicionalmente, dada a compreensão errônea da economia política da dinâmica de acumulação industrial característica do industrialismo do período Dilma, tal estratégia contribuiu também para deslegitimar politicamente a construção de uma agenda nacional de política industrial, inclusive entre as frações de classe representativas do capital industrial (Singer, 2015).

\section{Os limites da contribuição da indústria ao desenvolvimento nos governos Lula e Dilma: uma análise empírica a partir da decomposição estrutural}

Com o intuito de analisar empiricamente os limites da contribuição da indústria ao desenvolvimento nos governos Lula e Dilma, esta seção irá construir três exercícios de decomposição estrutural por meio de técnicas de shift share tal qual expressas em trabalhos como McMillan e Rodrik (2011); Unctad (2016) e Timmer e de Vries (2009).

A mensuração desta contribuição será analisada para variáveis relativas à (i) produtividade, (ii) remuneração média e (iii) sofisticação das exportações em relação às importações. Os efeitos serão segmentados segundo três componentes: intrasetorial, intersetorial estático e dinâmico.

Em outros termos, para o caso das variáveis relativas à produtividade, tem-se: 
Os limites da contribuição da indústria ao desenvolvimento nos períodos Lula e Dilma: uma nova versão do industrialismo periférico?

$$
\begin{gathered}
\Delta\left(L P_{T}\right)=\frac{L P_{T, f y}-L P_{T, b y}}{L P_{T, b y}}=I++I I+I I I \\
\text { onde: }
\end{gathered}
$$

I: transformação estrutural - efeito estático

$$
\overbrace{\sum_{i=1}^{n} L P_{i, b y}\left(S_{i, f y}-S_{i, b y}\right)}^{/ L P_{T, b y}}+
$$

II: transformação estrutural efeito dinâmico

$$
\overbrace{\sum_{i=1}^{n}\left(L P_{i, f y}-L P_{i, b y}\right)\left(S_{i, f y}-S_{i, b y}\right)}^{/ L P_{T, b y}}+
$$

$$
\overbrace{\sum_{i=1}^{n}\left(L P_{i, f y}-L P_{i, b y}\right) S_{i, b y}}^{\text {III: efeito intra setorial }}
$$

Sendo:

$\mathrm{T}=\Sigma$ de todos os setores i;

$\mathrm{S}_{\mathrm{i}}=$ participação do setor i no total do pessoal ocupado

$\left(=\mathrm{L}_{\mathrm{i}} / \mathrm{L}_{\mathrm{T}}\right)$

$f y=$ período final

by $=$ período inicial

LP = Produtividade do trabalho mensurada pela razão entre valor da transformação industrial e pessoal ocupado.

O primeiro termo refere-se à dimensão estática da transformação estrutural (inter setorial). Espera-se, em um processo exitoso de desenvolvimento, um aumento da participação relativa do emprego em setores com maior produtividade em paralelo à tendência de redução da participação relativa nos setores com menor produtividade, fatos estes que fariam com que este termo fosse positivo neste processo.

O segundo termo mensura a dimensão dinâmica da transformação estrutural (inter setorial) por meio da interação entre a variação da produtividade e a variação da participação do emprego em todos os setores da economia. Assim, espera-se que em uma transformação estrutural virtuosa o termo seja positivo, na medida em que haveria um crescimento relativo da produtividade maior que a média em setores que estariam concomitantemente aumentando sua participação no total do emprego.

Por fim, o terceiro termo mensura o crescimento da produtividade dentro de cada um dos setores (componente intrasetorial). Caso a variação desta seja positiva, independentemente da participação do setor no total do emprego na economia, a contribuição deste termo também será positiva. 
Cumpre destacar ainda que este mesmo esforço de mensuração será replicado tendo como variável a ser explicada a remuneração média e o grau de sofisticação das exportações em relação às importações. Os resultados esperados apresentam os mesmos comportamentos: uma trajetória exitosa de desenvolvimento está associada à contribuição positiva dos três efeitos para o aumento da remuneração média e do grau de sofisticação relativo das exportações. Por fim, cumpre enfatizar que será realizado um esforço adicional de agregação dos efeitos segundo tipos de tecnologia ou determinantes de competitividade (setores baseados em ciência, recursos naturais, intensiva em trabalho, intensiva em escala e diferenciados), com base na classificação expressa em OECD (1987) a partir de Pavitt (1984). Este esforço, por sua vez, permitirá analisar os limites das contribuições dos diferentes segmentos da indústria brasileira ao desenvolvimento.

Ao analisar o período de crescimento razoavelmente elevado nos governos Lula (2003 a 2010), com relação à produtividade, a primeira constatação é a de que esta apresenta-se praticamente estável (com crescimento acumulado de 1,8\% em 8 anos). Além dessa estabilidade, os dois blocos de setores de maior produtividade da indústria brasileira em 2003 apresentaram quedas consideráveis nestes valores no período (cerca de $17 \%$ para os baseados em ciência e 5,5\% para os intensivos em escala). Vale destacar também que até mesmo os setores intensivos em recursos naturais não mostraram grande dinamismo no aumento da produtividade $(+5,5 \%)$.

Quando se avalia a decomposição estrutural por meio de técnicas de shif-share, verifica-se que praticamente a totalidade do (pequeno) crescimento da produtividade é explicada pelo componente intrasetorial (Gráfico 4). Ou seja, não se observou um processo de mudança estrutural industrial capaz de contribuir para o desenvolvimento. Ao contrário do que seria desejável em uma trajetória virtuosa, a mudança estrutural contribuiu negativamente em setores com grande complexidade produtiva como intensivos em escala e diferenciados.

Gráfico 4

Decomposição Estrutural do Crescimento da Produtividade Brasileira, segundo tipos de tecnologia (2003 a 2010)

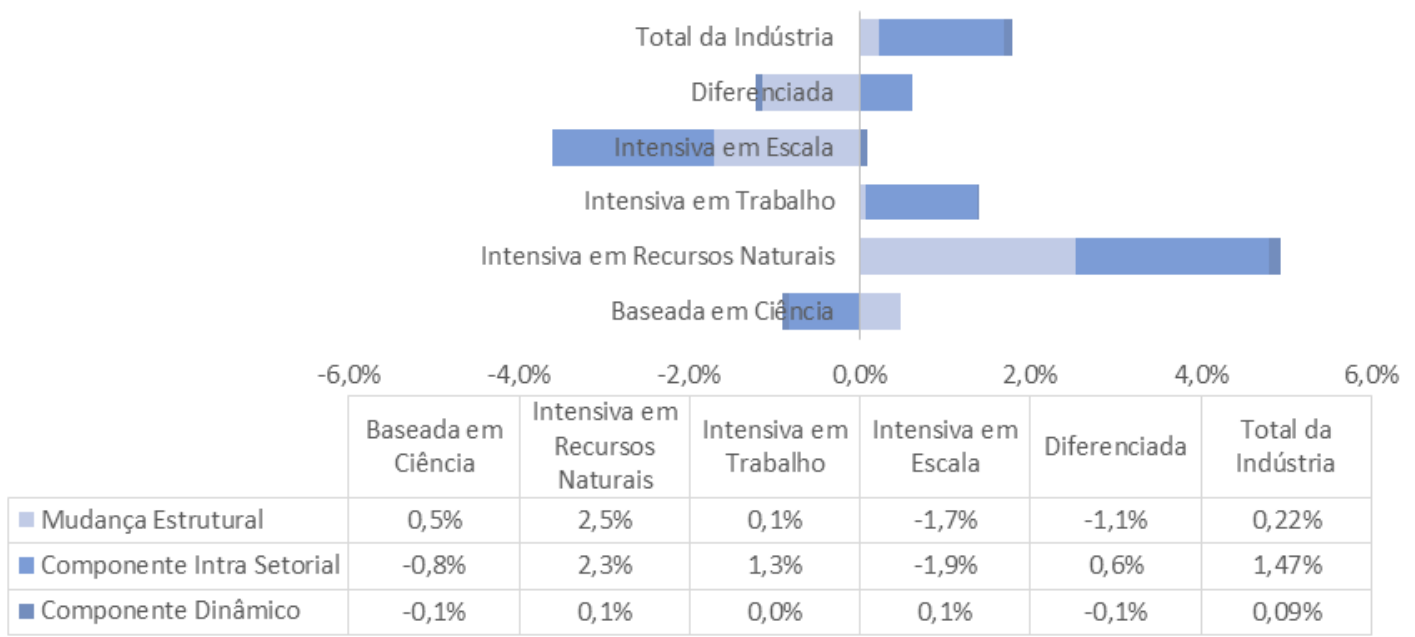

Fonte: Elaboração própria a partir de PIA - IBGE - Vários Anos. Classificação baseada em OECD (1987) a partir de Pavitt (1984). Dados deflacionados segundo IPA - FGV. Empresas com 30 ou mais pessoas ocupadas. 
O único bloco de setores que se comportou de maneira esperada para uma trajetória virtuosa de desenvolvimento foi o de intensivos em recursos naturais. Apesar de também não ter mostrado elevado crescimento da produtividade, conforme citado anteriormente, tanto o componente intrasetorial quanto o de mudança estrutural foram positivos. Este componente estrutural, vale destacar, é o que apresenta maior contribuição positiva para a estrutura produtiva brasileira no período entre todos os blocos de setores. Uma vez que os setores intensivos em recursos naturais representaram $35 \%$ do pessoal ocupado na indústria brasileira no final do período, compreende-se os determinantes da magnitude desta contribuição.

Com relação à remuneração média ${ }^{3}$ no período Lula (Gráfico 5) observa-se uma tendência de crescimento contínuo e generalizado. Apesar de espraiado por todos os setores, aqueles intensivos em recursos naturais e em trabalho foram responsáveis conjuntamente por $88 \%$ deste crescimento (54\% para os primeiros e $34 \%$ para os segundos). Entretanto, a despeito deste dinamismo, cabe destacar que praticamente a totalidade deste é devida ao componente intrasetorial. Ou seja, não se observa a contribuição da mudança estrutural (estática e dinâmica) para o aumento das remunerações médias, fato este que seria o mais adequado em uma estratégia de desenvolvimento virtuosa com o redirecionamento das ocupações para atividades com maior produtividade e maiores remunerações, tal qual expresso na seção 1 .

Gráfico 5

Decomposição Estrutural do Crescimento da Remuneração Média do pessoal assalariado na Indústria Brasileira, segundo tipos de tecnologia (2003 a 2010)

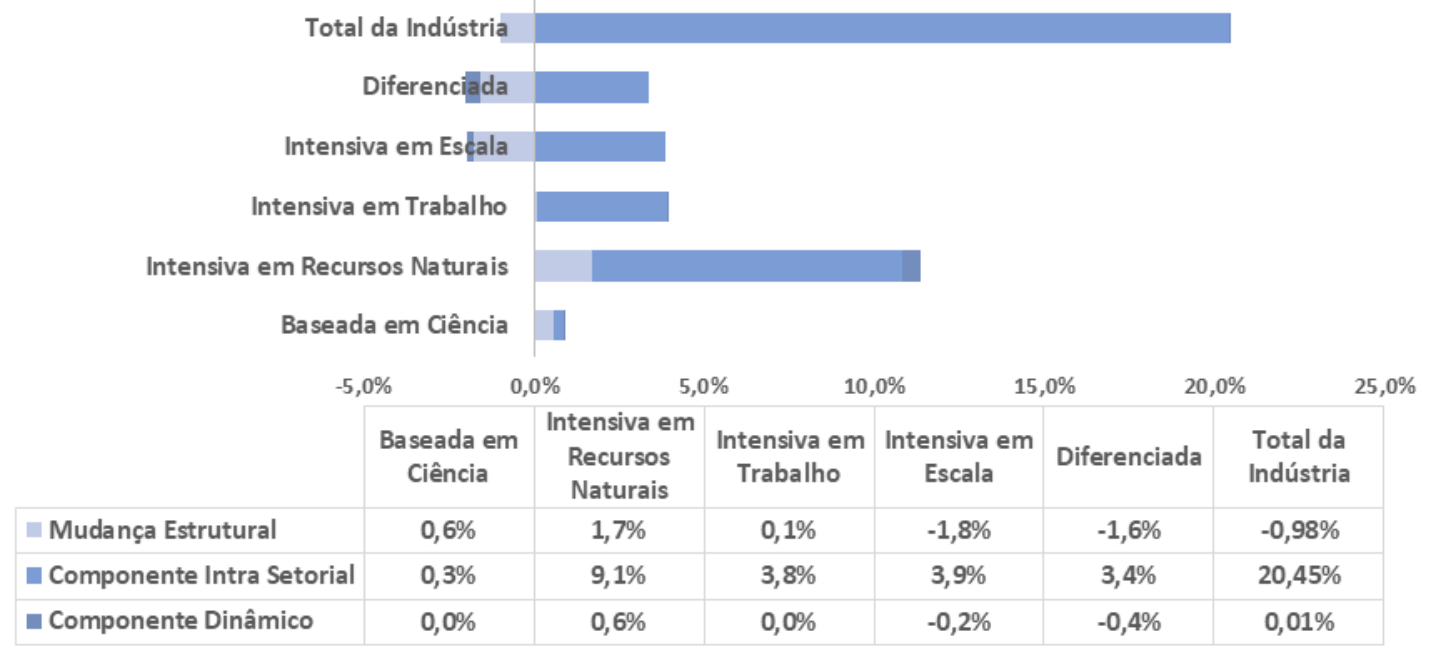

Fonte: Elaboração própria a partir de PIA - IBGE - Vários Anos. Classificação baseada em OECD (1987) a partir de Pavitt (1984). Dados deflacionados segundo IPA - FGV. Empresas com 30 ou mais pessoas ocupadas.

Outra limitação refere-se ao fato de que o crescimento do componente intrasetorial é muito mais explicado pela dinâmica do mercado de trabalho e do comportamento geral da remuneração média da economia do que por fatores relacionados à indústria de transformação. Assim, apesar do crescimento generalizado e em patamares razoavelmente elevados, este ocorre em dimensões muito semelhantes (entre $20 \%$ e $24 \%$ ) da evolução do rendimento médio da economia brasileira e também

(3) A remuneração média, coletada a partir da tabela 1841 da Pesquisa Industrial Anual - Empresa - IBGE, diz respeito aos salários e outras remunerações pagas às pessoas assalariadas, seja em funções ligadas à produção ou não. 
do setor de serviços - conforme dados da PNAD e da Pesquisa Anual de Serviços do IBGE. Ou seja, mesmo ao apresentar contribuição positiva para o desenvolvimento nos termos abordados neste trabalho, essa contribuição não parece ser derivada de uma transformação estrutural compatível com uma estratégia virtuosa de desenvolvimento.

Por fim, quando se analisa o grau de sofisticação das exportações em relação às importações, também se observa a tendência de redução da capacidade de contribuição da indústria ao desenvolvimento. Mensurado a partir da razão entre os valores médios de importações e exportações ponderados pela participação de cada produto nos totais importados e exportados, esse indicador sai de 0,92 para 1,12 entre 2003 e 2010. Ou seja, apesar do grande boom do ciclo das commodities, as importações industriais brasileiras no período tiveram seus valores aumentados em $21 \%$ a mais do que o das exportações industriais. Ao se analisar a evolução anual destes indicadores, observa-se ainda que a tendência de piora desta razão se acentua em momentos de pujança econômica doméstica, o que traz elementos no sentido de se identificar a fragilidade da estrutura produtiva local sustentar uma trajetória de desenvolvimento virtuoso com redução da restrição externa.

Quando se mensura o comportamento a partir da decomposição estrutural das exportações (Gráfico 6), verifica-se uma redução de cerca de $13,3 \%$ dos valores $/ \mathrm{kg}$, sendo explicada totalmente pelo componente intrasetorial (que teve queda de 17,7\%). Os principais setores que contribuíram para esse movimento foram os diferenciados e intensivos em escala. Ao se examinar detalhadamente os determinantes da decomposição estrutural, as exportações dos setores intensivos em escala parecem ser fundamentais para o fomento de uma estratégia virtuosa de desenvolvimento industrial brasileiro, uma vez que representaram em 2010 quase 42\% das exportações brasileiras e apresentaram invariavelmente os maiores valores / $\mathrm{kg}$. Vale destacar que, apesar do boom das commodities no período, dado o baixo valor / $\mathrm{kg}$ dessas mercadorias em face do valor médio do total das exportações brasileiras, os setores intensivos em recursos naturais não contribuíram significativamente para variações nos componentes intrasetorial e intersetorial / mudança estrutural.

Gráfico 6

Decomposição Estrutural da variação do preço das exportações industriais brasileiras, segundo tipos de tecnologia (2003 a 2010)

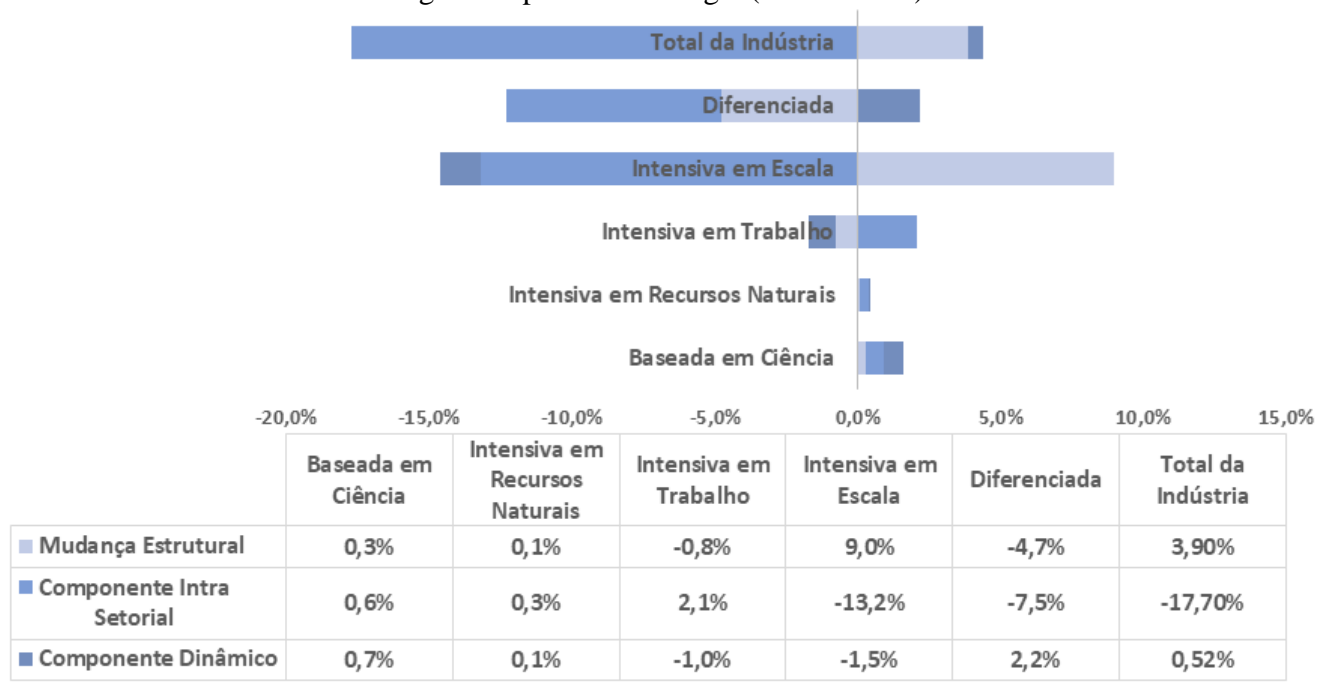

Fonte: Elaboração própria a partir de TRADE MAP - Vários Anos. Classificação baseada em OECD (1987) a partir de Pavitt (1984). 
Já com relação às importações (Gráfico 7) observa-se um movimento inverso, com aumento dos valores $/ \mathrm{kg}$, explicado fundamentalmente pelo componente intrasetorial dos setores baseados em ciência e diferenciados. Esta tendência contribui no sentido de mostrar que durante o ciclo de relativa pujança econômica no período Lula, a indústria brasileira foi incapaz de viabilizar um processo virtuoso que combinasse crescimento com transformação estrutural e viabilizasse a gradativa substituição do atendimento da demanda importada com maior valor agregado pela produção doméstica.

Gráfico 7

Decomposição Estrutural da variação do preço das importações industriais brasileiras, segundo tipos de tecnologia (2003 a 2010)

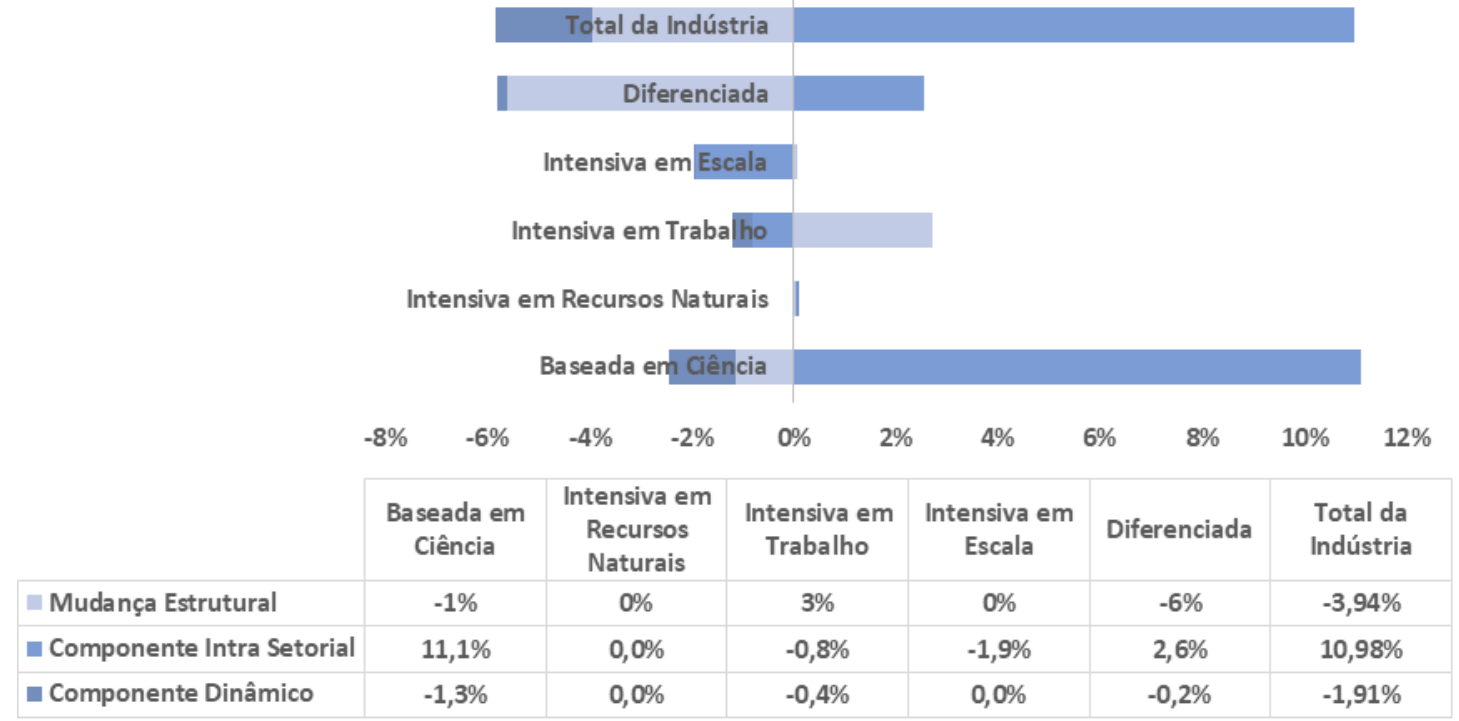

Fonte: Elaboração própria a partir de TRADE MAP - Vários Anos. Classificação baseada em OECD (1987) a partir de Pavitt (1984).

Cumpre enfatizar ainda que o movimento de aumento do valor médio das importações industriais brasileiras ocorre em um período em que o acirramento da concorrência internacional na indústria por parte da consolidação da fábrica asiática exerceu forte pressão baixista sobre o preço dos produtos manufaturados. Esse movimento pode ser inferido a partir da variação fortemente negativa do componente mudança estrutural para os setores diferenciados (nos quais se concentra parcela significativa dos produtos do complexo eletrônico, os quais foram os principais vetores desta pressão baixista citada).

Em síntese, ao se analisar os governos Lula (2003 a 2010) ficam patentes os limites da contribuição da indústria ao desenvolvimento, mesmo em um período de relativa pujança. Esses limites decorrem principalmente das evidências de um processo de regressão estrutural em direção a atividades e setores com menor complexidade produtiva e tecnológica, e da deterioração do grau de sofisticação das exportações em relação às importações, apesar das pressões altistas dos preços das commodities e baixistas dos preços dos manufaturados. Adicionalmente, verificou-se que o 
crescimento das remunerações foi muito semelhante ao da média da economia, sendo concentrado em setores intensivos em recursos naturais e trabalho, e não impulsionado por um processo de mudança estrutural.

Nesta mesma direção, Cano e Gonçalves (2010) concluem que essas limitações também são intrínsecas à economia política da política industrial do período. Segundo eles

há acertos nas tentativas de fusão e resolução de problemas estruturais de grandes empresas nacionais, inclusive para tentar fortalecê-las futuramente em termos de presença internacional. Ao mesmo tempo, não há nenhuma estratégia macroeconômica e industrial para que seja sustentável e exequível a fim de enfrentar a desindustrialização.

E, em seguida concluem que

Não há Política Industrial que consiga contrabalançar os efeitos perversos de uma política macroeconômica com taxa de câmbio e de juros persistentemente limitando a eficácia dos instrumentos de financiamento e aumentando a aversão ao risco empresarial", (Isso porque) "Esta contradição entre as políticas industrial e macroeconômica reflete, na verdade, as divisões que existem dentro do Estado brasileiro, que, em última instância, refletem divisões dentro da sociedade acerca do projeto que se pretende para o país (Cano; Gonçalves, p. 201).

Ao analisar o período de desaceleração e posterior recessão nos governos Dilma (2011 a 2015), a constatação é a de que há uma tendência quase generalizada de piora da capacidade de contribuição da indústria ao desenvolvimento devido ao esgotamento do modelo de crescimento vigente até então.

Com relação à produtividade, observa-se uma queda de $0,5 \%$ no período. Assim como no período anterior, os setores intensivos em escala mantiveram a tendência de queda e os intensivos em trabalho permaneceram com taxas positivas de crescimento na dimensão intrasetorial. O primeiro grande destaque é o fato de os setores intensivos em recursos naturais reverterem seu comportamento, ao apresentarem durante 5 anos uma queda de produtividade de 4,7\%. Apesar do esgotamento do ciclo de commodities vigente no período Lula, tal queda está longe de ser desprezível.

Quando se analisa a variação da produtividade a partir da decomposição estrutural via shif share (Gráfico 8), os limites da contribuição da indústria ao desenvolvimento brasileiro tornam-se ainda mais patentes. Com exceção dos setores intensivos em recursos naturais, observa-se uma contribuição negativa do efeito mudança estrutural para todos os blocos de setores, ao contrário do que seria esperado a partir de uma estratégia de desenvolvimento virtuosa que viabilizasse a transição da força de trabalho para atividades mais complexas e produtivas. Não obstante esta constatação, a contribuição positiva do efeito mudança estrutural por parte dos setores intensivos em recursos naturais merece uma ressalva. Isso porque apesar de ser positiva, os esses setores reduziram sua produtividade. 
Os limites da contribuição da indústria ao desenvolvimento nos períodos Lula e Dilma: uma nova versão do industrialismo periférico?

Gráfico 8

Decomposição Estrutural do Crescimento da Produtividade Brasileira, segundo tipos de tecnologia (2011 a 2015)

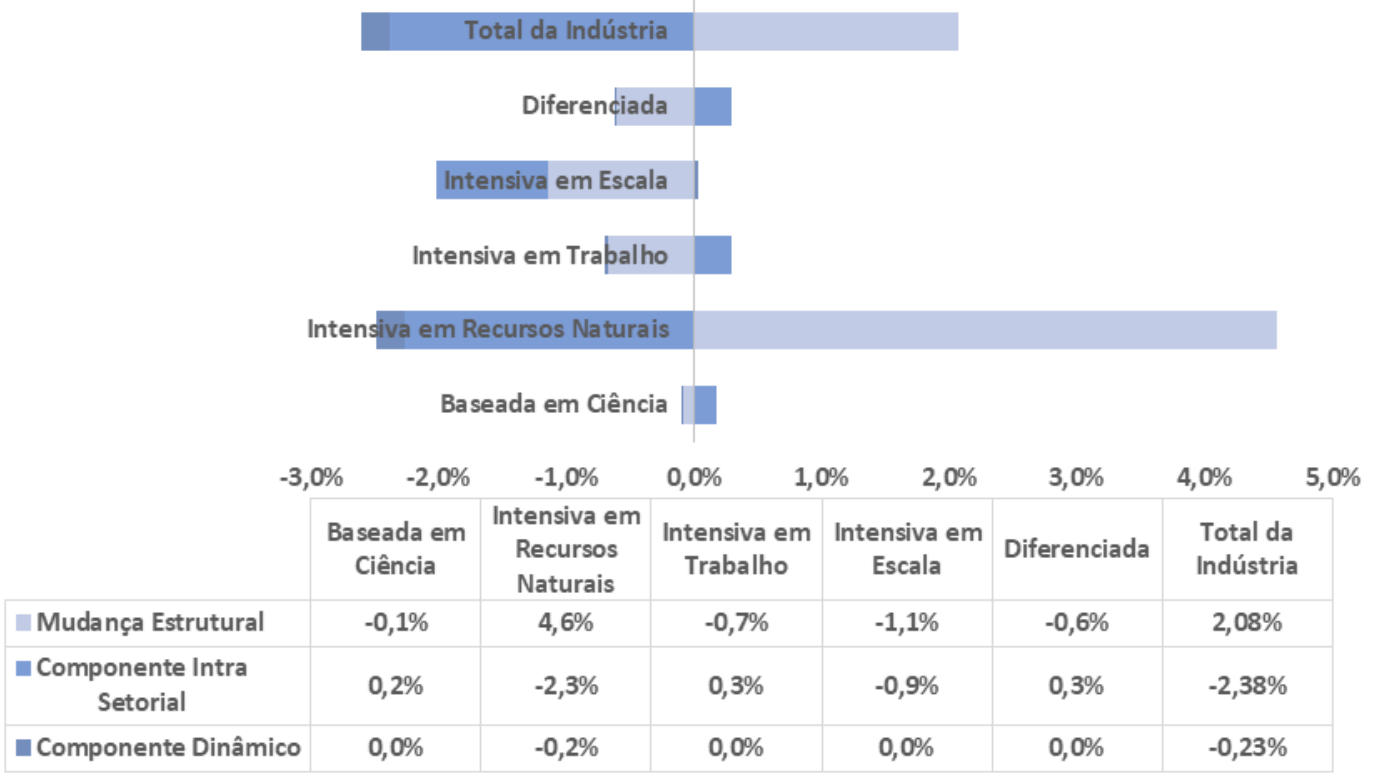

Fonte: Elaboração própria a partir de PIA - IBGE - Vários Anos. Classificação baseada em OECD (1987) a partir de Pavitt (1984). Dados deflacionados segundo IPA -FGV. Empresas com 5 ou mais pessoas ocupadas.

Assim, a explicação para essa contribuição positiva deve ser compreendida a partir da interação de dois elementos. O primeiro deles é o fato de que, apesar da queda da produtividade destes setores, esta ainda é maior que a produtividade média de todos os setores da indústria. O segundo elemento é que estes aumentaram a sua participação no total de pessoal ocupado na indústria brasileira de $35,7 \%$ para 39,1\% em 2015. Assim, a despeito da queda da produtividade intrasetorial dos setores intensivos em recursos naturais, observou-se uma espécie de migração de pessoal ocupado de setores com menor produtividade para este setor, que ainda assim apresenta produtividade maior que a média. Daí decorre o fato de a mudança estrutural ter contribuído positivamente no período. Deste modo, conclui-se que mesmo o único bloco de setores com contribuição positiva do componente mudança estrutural não fundamenta tal contribuição em uma estratégia virtuosa de transformação com crescimento da produtividade.

A tendência de deterioração da capacidade de contribuição da indústria ao desenvolvimento nos governos Dilma também pode ser observada quando se analisa a remuneração média (Gráfico 9). Apesar da continuidade do crescimento generalizado - de 8,6\% no período - mesmo em um cenário de desaceleração, a tendência já observada nos governos Lula se acentua: a variação da remuneração foi explicada fundamentalmente pela dinâmica do mercado de trabalho e pelo comportamento geral da remuneração média da economia ao invés de decorrer de fatores relacionados à indústria. Ou seja, apesar da desaceleração, a manutenção de baixos índices de desemprego e a continuidade da política de reajustes reais dos salários-mínimos - mesmo em patamares menores pós 2013 - contribuiu indiretamente para a continuidade do crescimento da remuneração na indústria. 
Outro sintoma desta dependência da dinâmica do mercado de trabalho extra indústria pode ser verificada a partir da constatação de que o componente mudança estrutural contribuiu negativamente para o aumento da remuneração em todos os blocos de setores, com exceção dos intensivos em recursos naturais.

\section{Gráfico 9}

Decomposição Estrutural do Crescimento da Remuneração Média do pessoal assalariado na Indústria Brasileira, segundo tipos de tecnologia (2011 a 2015)

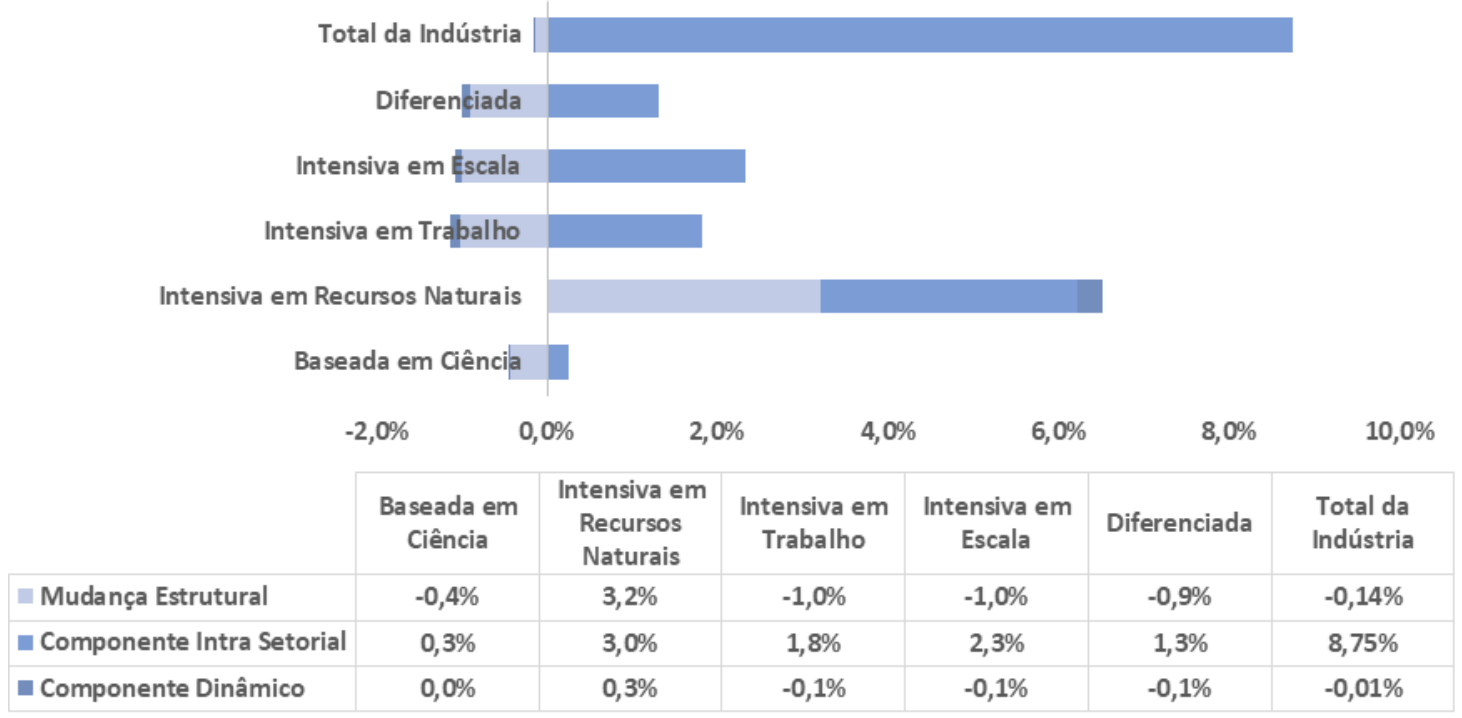

Fonte: Elaboração própria a partir de PIA-IBGE - Vários Anos. Classificação baseada em OECD (1987) a partir de Pavitt (1984). Dados deflacionados segundo IPCA. Empresas com 5 ou mais pessoas ocupadas.

Com relação ao grau e sofisticação das exportações em relação às importações, o movimento também observado no período Lula se reapresenta, agora com ainda maior intensidade: a relação entre os valores médios das importações e das exportações aumenta 12\% em apenas 5 anos, mesmo em um cenário de desaceleração econômica. Ou seja, verifica-se uma relativa incapacidade de redução relativa da importação de produtos de maior valor agregado independentemente do ciclo econômico, fato este que também contribui para sinalizar a fragilidade crescente da estrutura produtiva doméstica.

Para as importações, este movimento é explicado principalmente pelo aumento substancial do componente intrasetorial, com grande destaque para os setores diferenciados, seguidos por intensivos em escala e baseados em ciência, o que seria mais um elemento para corroborar a fragilidade expressa no parágrafo anterior (Gráfico 10). 
Os limites da contribuição da indústria ao desenvolvimento nos períodos Lula e Dilma: uma nova versão do industrialismo periférico?

Gráfico 10

Decomposição Estrutural da variação do preço das importações industriais brasileiras, segundo tipos de tecnologia (2011 a 2015)

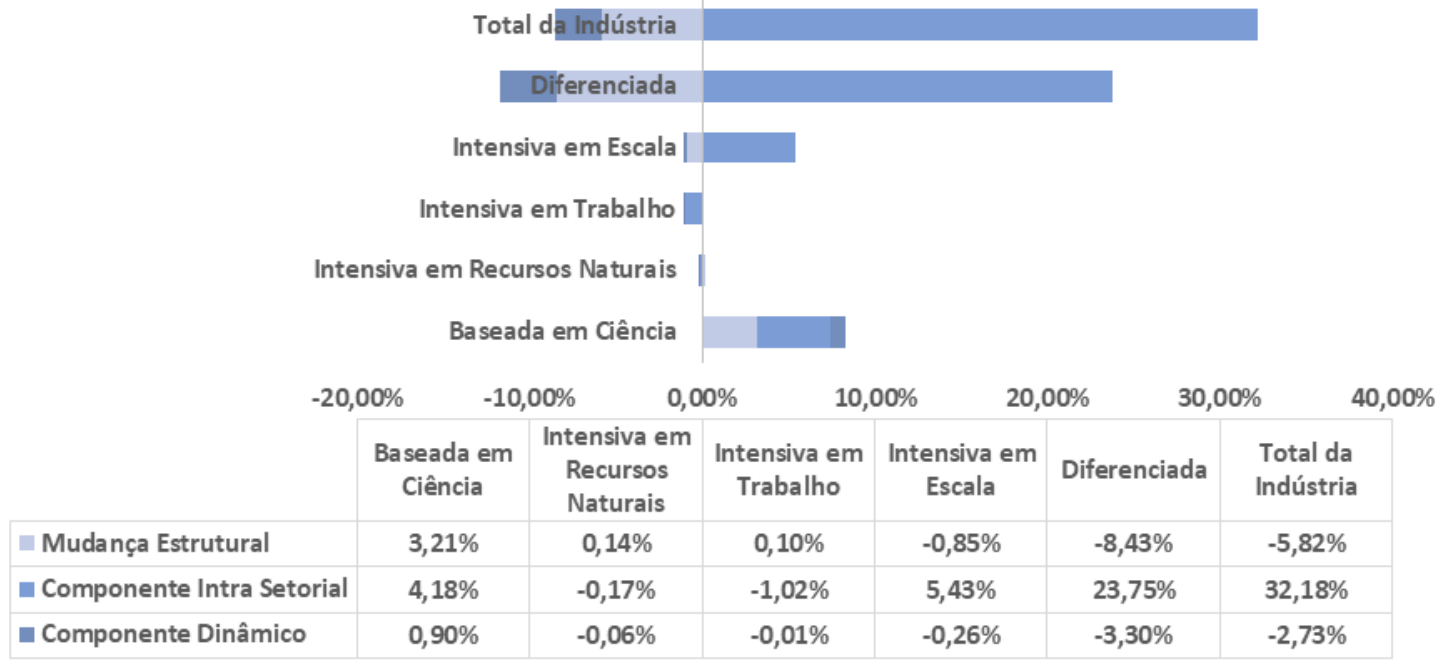

Fonte: Elaboração própria a partir de TRADE MAP - Vários Anos. Classificação baseada em OECD (1987) a partir de Pavitt (1984).

Gráfico 11

Decomposição Estrutural da variação do preço das exportações industriais brasileiras,

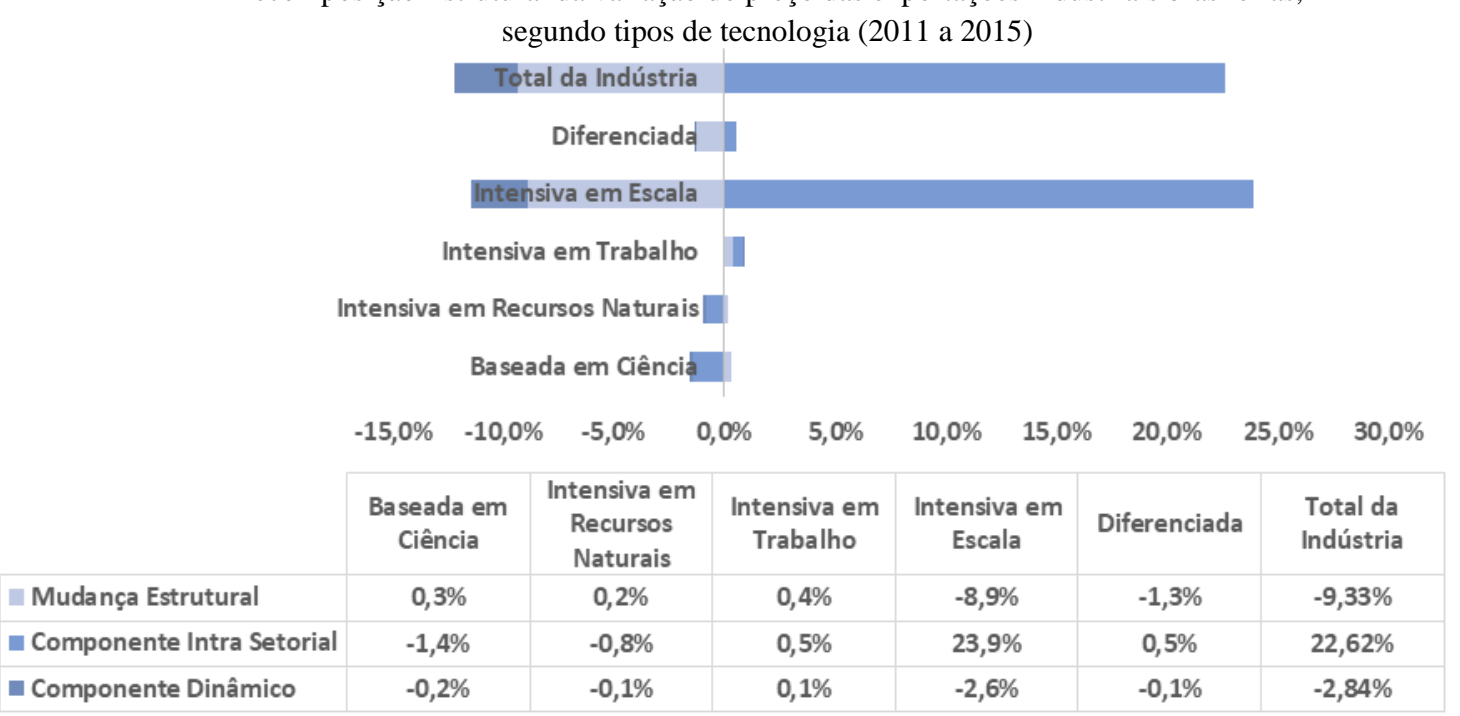

Fonte: Elaboração própria a partir de TRADE MAP - Vários Anos. Classificação baseada em OECD (1987) a partir de Pavitt (1984).

Esse movimento é parcialmente amortizado pelo efeito positivo do componente intersetorial das exportações dos setores intensivos em escala, os quais apresentaram uma forte recuperação dos preços pós efeitos da crise de 2008 (Gráfico 11). Dentro destes setores, parte substancial da contribuição para esta variação positiva de preços decorre do complexo aeronáutico (dados seus 
elevados valores agregados). Assim, com exceção deste comportamento notável, também não se observa no período um processo de transformação da pauta exportadora em direção a atividades mais nobres e com maior valor agregado.

Como conclusão da análise dos limites da contribuição da indústria ao desenvolvimento no período Dilma (2011 a 2015), observa-se um acirramento das tendências verificadas nos governos Lula. Esse acirramento combina uma tendência quase generalizada de contribuição negativa dos efeitos de mudança estrutural para a variável produtividade e para a remuneração industrial, em paralelo à deterioração do grau de sofisticação das exportações em relação às importações principalmente em setores de alta complexidade produtiva e tecnológica.

\section{Considerações finais}

Este artigo buscou analisar os limites da contribuição da indústria ao desenvolvimento brasileiro nos governos Lula e Dilma. A partir da utilização de esforços de decomposição estrutural baseados na metodologia de shif-share, tais limites foram analisados em dois cenários qualitativamente distintos: o ciclo de aceleração do crescimento entre 2003 e 2010 e a desaceleração e reversão entre 2011 e 2015.

Como principais contribuições do trabalho à literatura, destaca-se a mensuração empírica da incapacidade da indústria brasileira viabilizar uma estratégia de desenvolvimento virtuosa, caracterizada pela reconfiguração da estrutura produtiva em direção a atividades com maior nível de produtividade, maiores níveis de salariais e que viabilizem maior sofisticação das exportações, tal qual sugerem as interpretações teóricas clássicas e de origem estruturalista ao analisarem a relação entre indústria e desenvolvimento econômico, bem como a obra de Wilson Cano. Mostrou-se ainda que essa incapacidade parece ser de natureza estrutural, uma vez que é característica tanto no ciclo de relativa pujança econômica dos governos Lula quanto na posterior desaceleração e reversão verificada no período Dilma. Uma última contribuição do artigo é a constatação destes limites serem relativamente generalizados entre os setores econômicos com maior complexidade produtiva e tecnológica, com destaque para os diferenciados e intensivos em escala.

Especificamente para os governos Lula (2003 a 2010) os limites da contribuição da indústria ao desenvolvimento materializam-se nas seguintes constatações:

(i) não se observou um processo de mudança estrutural em direção a atividades com maior produtividade. Ao contrário, verificaram-se evidências de um processo de regressão estrutural principalmente em setores com maior complexidade produtiva e tecnológica;

(ii) apesar do crescimento da remuneração média, este foi explicado quase que totalmente pelos setores intensivos em recursos naturais e em trabalho, e não decorreu de um processo de mudança estrutural. Ou seja, este fenômeno parece ter sido derivado mais da dinâmica do mercado de trabalho e do comportamento geral da remuneração média da economia - dado o sólido aumento do salário-mínimo no período e a aproximação da situação de pleno emprego no final do período Lula - do que por fatores relacionados à indústria;

(iii) observou-se uma tendência de deterioração do grau de sofisticação das exportações em relação às importações, com redução dos preços das primeiras e aumento das segundas. Destaca- 
se ainda que tal fato ocorreu a despeito dos impactos positivos do Efeito China, com pressões altistas no preço das commodities internacionais e baixistas nos produtos manufaturados.

Por fim, no período Dilma (2011 a 2015) os limites da contribuição da indústria ao desenvolvimento já observados no ciclo Lulista de relativa pujança mostram-se ainda mais presentes, uma vez que:

(i) verificou-se a contribuição negativa do componente de mudança estrutural para a variável produtividade em todos os blocos de setores industriais, com exceção dos intensivos em recursos naturais - ao contrário do que sugeriria uma estratégia virtuosa de desenvolvimento. Estes últimos, apesar de contribuírem positivamente, o fizeram exclusivamente porque aumentaram sua participação no total de pessoal ocupado, dado que sua produtividade também se reduziu (apesar de ser maior que a média dos outros setores);

(ii) apesar de manter a trajetória de crescimento mesmo em um cenário de desaceleração cíclica, a variação do salário médio industrial continuou sendo fundamentalmente determinada pela dinâmica do mercado de trabalho e não por fatores essencialmente industriais. Isso porque, de maneira ainda mais intensa do que no período Lula, o componente mudança estrutural contribuiu negativamente para o aumento da remuneração em todos os blocos de setores, com exceção dos intensivos em recursos naturais;

(iii) a deterioração do grau de sofisticação das exportações em relação às importações se acentuou ainda mais - sendo explicada fundamentalmente pela dependência estrutural da importação em setores de alta complexidade produtiva e tecnológica, independentemente da reversão do ciclo econômico doméstico.

Neste cenário, o artigo traz elementos que sugerem a consolidação de um padrão de organização estrutural da indústria brasileira que limita sua capacidade de contribuição ao desenvolvimento com relativo grau de independência dos econômicos. Esse padrão é gestado a partir do último quartel do século XX, amadurece na primeira década dos anos 2000 e é consolidado na década seguinte, e dá origem ao fenômeno aparentemente contraditório que este artigo sugere que seja interpretado como uma nova versão do industrialismo periférico (e agora regressivo). A consolidação deste padrão, por sua vez, ocorre concomitantemente ao estabelecimento das novas formas de produção modularizadas no âmbito das cadeias globais de valor. Neste cenário, a liberalização comercial e financeira se configurou como um instrumento para viabilizar a emergência de uma nova dinâmica de produção e acumulação do parque produtivo periférico brasileiro. Essa dinâmica de acumulação, ao contrário do que sugeririam interpretações baseadas no arcabouço teórico produtivista fordista / chandleriano característico da II Revolução Industrial, se beneficiaria do avanço da liberalização. Na dimensão internacional, os benefícios decorreriam do aprofundamento da estratégia de integração periférica dependente de elos menos nobres das cadeias globais de valor, com o avanço da complementaridade subordinada ao capital produtivo internacional, atuando em atividades vinculadas à representação deste (comercial, financeira e de marketing), à tropicalização de produtos importados e à maquila às avessas - dado que orientada ao consumo doméstico. Já na dimensão interna, a dinâmica de produção e acumulação baseada nessa nova versão do industrialismo periférico seria caracterizada pela incapacidade de se incrementar a competitividade por meio de um processo virtuoso de transformação estrutural. Ao contrário, seria cada vez mais sustentada na busca 
pelo aumento da rentabilidade relativa do capital industrial por meio da redução de custos diretos, indiretos e de tributação, e não necessariamente pelo aumento da complexidade dos processos produtivos e pelo conseguinte aumento da produtividade. Assim, como afirma Cano, "o modelo atual, além de estar divorciado da industrialização, é incapaz de manter taxas anuais de crescimento elevadas e persistentes a longo prazo". Deste modo, para os "desenvolvimentistas" seria "urgente (a) necessidade de retomar não só o crescimento, mas também a competitividade industrial, seriamente abalada" (Cano, 2010, p. 32). E conclui:

Para os críticos, contudo, isso é necessário, mas é apenas parte do que deveria constituir o novo projeto, que deveria ter, como vetor político central, o ataque frontal a nossas desigualdades maiores e uma verdadeira estratégia de retomada da industrialização, com vista a um crescimento econômico mais bem ambientalmente sustentado (Cano, 2010, p. 32).

\section{Referências bibliográficas}

ANDREONI A.; CHANG, H. J. The political economy of industrial policy: structural interdependencies, policy alignment and conflict management. Special issue: frontiers of industrial policy: structures, institutions and policies. Eds.: ANDREONI, A.; CHANG, H.-J.; SCAZZIERI, R. Structural change and economic dynamics, 48, p. 136-150. 2019.

ANDREONI, A.; GREGORY, M. Why and how does manufacturing still matter: old rationales, new realities. Revue d'Economie Industrielle, v. 144, n. 4, p. 21-57, 2013.

ALMEIDA, Julio Sergio Gomes; NOVAIS, Luis Fernando; ROCHA, Marco Antonio. A fragilização financeira das empresas não financeiras no Brasil pós-crise. Campinas: Unicamp. IE, 2016. (Texto para Discussão, n. 281).

BERGER, S. Making in America: from innovation to market. London: The MIT Press, 2013, 264p.

BRESSER-PEREIRA, Luiz Carlos. Doença holandesa e sua neutralização: uma abordagem ricardiana. Doença holandesa e a indústria. Rio de Janeiro: Editora da Fundação Getúlio Vargas, 2008.

BRESSER-PEREIRA, Luiz Carlos. Brasil vive desindustrialização. Folha de S. Paulo, 2010.

BRESSER-PEREIRA, Luiz Carlos. The value of the exchange rate and the dutch disease. Revista de Economia Política, v. 33, n. 3 (132), p. 371-387, jul./set. 2013.

BRESSER-PEREIRA, Luiz Carlos; MARCONI, N. Existe doença holandesa no Brasil? In: BRESSER-PEREIRA, L. C. (Org.). Doença holandesa e indústria (Coletânea). Rio de Janeiro: Editora FGV, 2010.

BRUN, L.; GEREFFI, G.; ZHAN, J. The "lightness" of Industry 4.0 lead firms: implications for global value chains. In: BIANCHI, P.; DURÁN, C. R.; LABORY, S. (Ed.). Transforming industrial policy for the digital age - Production, territories and structural change. Edward Elgar Publishing Limited, 2019.

CANO, W. Uma agenda nacional para o desenvolvimento. Revista Tempo no Mundo, Brasília, Ipea, v. 2, n. 2, dez. 2010. 
Os limites da contribuição da indústria ao desenvolvimento nos períodos Lula e Dilma: uma nova versão do industrialismo periférico?

CANO, W.; GONÇALVES, A. L. Política industrial do governo Lula. In: OS ANOS Lula: contribuições para um balanço crítico 2003-2010. Rio de Janeiro: Garamond Editora, 2010.

CANO, W. A desindustrialização no Brasil. Economia e Sociedade, Campinas, v. 21, Número Especial, p. 831-851, dez. 2012.

CANO, W. (Des)industrialização e (sub)desenvolvimento. Cadernos do Desenvolvimento, Rio de Janeiro, v. 9, n. 15, p. 139-174, jul./dez. 2014.

CARNEIRO, Ricardo. Desenvolvimento em crise: a economia brasileira no último quarto do século XX. São Paulo: Editora Unesp / IE - Unicamp, 2002.

CARNEIRO, R. Navegando a contravento: uma reflexão sobre o experimento desenvolvimentista do governo Dilma Rousseff. In: CARNEIRO, R.; BALTAR, P.; SARTI, F. (Org.). Para além da política econômica. São Paulo: Editora Unesp Digital, 2018.

CARVALHO, L. Valsa brasileira: do boom ao caos econômico. São Paulo: Todavia, 2018.

CEMEC-IBMEC. Análise da composição do exigível financeiro das companhias abertas e fechadas não financeiras. São Paulo: IBMEC, 2014.

CEMEC-IBMEC. Nota CEMEC - Fatores da queda do investimento 2010-2014. São Paulo: IBMEC, 2015.

CHANG, Há-Joon. The political economy of industrial policy in Korea. London: Macmillan Press, 1994.

CHANG, Há-Joon. Chutando a escada: a estratégia de desenvolvimento em perspectiva histórica. São Paulo: Ed. Unesp, 2004.

COUTINHO, L. C. A especialização regressiva: um balanço do desempenho industrial pósestabilização. In: VELLOSO, J. P. R. (Org.). Brasil: desafios de um país em transformação. Rio de Janeiro: José Olympio Editora, 1997.

DIEGUES, A. C.; ROSSI, C. G. Além da desindustrialização: transformações no padrão de organização e acumulação da indústria em um cenário de 'Doença Brasileira'. Campinas: Unicamp. IE, 2017. (Texto para Discussão, n. 291). Aceito para publicação na Revista Economia e Sociedade.

DIEGUES, A. C.; ROSELINO, J. E. Indústria 4.0 e as redes globais em serviços intensivos tecnologia: apontamentos sobre política industrial e considerações para o caso brasileiro. Campinas: Unicamp. IE, 2019. (Texto para Discussão, n. 356).

FURTADO, Celso. Desenvolvimento e subdesenvolvimento (1961). In BIELSCHOWSKY, Ricardo (Org). Cinquenta anos de pensamento na Cepal. Rio de Janeiro: Cofecon-Cepal; Record, 2000. v. I.

GERSCHENKRON, Alexander. El atraso económico en su perspectiva histórica. In: GERSCHENKRON, A. El atraso económico en su perspectiva histórica. Barcelona: Ariel, 1973.

HAMILTON, Alexander (1791). Report on manufactures.

HIRSCHMAN, Albert. The strategy of economic development. New Haven: Yale University Press, 1958. v. 10. 
HIRATUKA, Célio; ROCHA, Marco Antonio. Grandes grupos no Brasil: estratégias e desempenho nos anos 2000. Brasília: Ipea, 2015. (Texto de Discussão).

HIRATUKA, Célio; SARTI, Fernando. Transformações na estrutura produtiva global, desindustrialização e desenvolvimento industrial no Brasil: uma contribuição ao debate. Campinas: Unicamp. IE. 2015. (Texto para Discussão, n. 290).

KALDOR, Nicholas. Causes of the slow rate of economic growth of the United Kingdom. Cambridge: Cambridge University Press, 1966.

KALDOR, Nicholas. Problems of industrialization in underdeveloped countries. Ithaca: Cornell University Press, 1967.

LEWIS, W. A. O desenvolvimento econômico com oferta ilimitada da mão-de-obra. In: AGARWAZA, A. N.; SINGH, S. P. (Coord.). A economia do subdesenvolvimento. São Paulo: Forense, 1969.

LIST, Georg F. (1841). Sistema nacional de economia política. São Paulo: Nova Cultural, 1989.

MCMILLAN, M. S.; RODRIK, D. Globalization, structural change and productivity growth. National Bureau of Economic Research, 2011.

MELLO, G.; ROSSI, P. Do industrialismo à austeridade: a política macro dos governos Dilma. In: CARNEIRO, R.; BALTAR, P.; SARTI, F. (Org.). Para além da política econômica. São Paulo: Editora Unesp Digital, 2018.

MORCEIRO, Paulo. Desindustrialização na economia brasileira no período 2000-2011: abordagens e indicadores. Dissertação (Mestrado em Economia)-Universidade Estadual Paulista, Faculdade de Ciências e Letras, Campus de Araraquara, Araraquara, 2012.

MORCEIRO, Paulo. A indústria brasileira no limiar do século XXI: uma análise da sua evolução estrutural, comercial e tecnológica. Tese (Doutorado)-Universidade de São Paulo, São Paulo, 2018.

ORGANIZATION FOR ECONOMIC COOPERATION AND DEVELOPMENT. Structural adjustment and economic performance. Paris: Organization for Economic Cooperation and Development, 1987. 371p.

ORGANIZATION FOR ECONOMIC COOPERATION AND DEVELOPMENT. OECD science, technology and industry scoreboard 2005. Paris: Organization for Economic Cooperation and Development, 2005. 210p.

OREIRO, José Luís; FEIJÓ, Carmem. Desindustrialização: conceituação, causas, efeitos e o caso brasileiro. Revista de Economia Política, v. 30, n. 2 (118), p. 219-232, 2010.

O'SULLIVAN, E.; ANDREONI, A.; LÓPEZ-GÓMEZ, C.; GREGORY, M. What is new in the new industrial policy? A manufacturing systems perspective. Oxford Review of Economic Policy, v. 29, n. 2, p. 432-462, 2013.

PALMA, José Gabriel. Quatro fontes de desindustrialização e um novo conceito de doença holandesa. In: CONFERÊNCIA de Industrialização, Desindustrialização e Desenvolvimento. Federação das Indústrias do Estado de São Paulo, 2005. 
Os limites da contribuição da indústria ao desenvolvimento nos períodos Lula e Dilma: uma nova versão do industrialismo periférico?

PAVITT, K. Sectoral patterns of technical change: towards a taxonomy and a theory. Research Policy, n. 13, p. 343-373, 1984.

PINTO, Aníbal (1970). Natureza e implicações da 'heterogeneidade estrutural na América Latina. In: BIELSCHOWSKY, Ricardo (Org). Cinquenta anos de pensamento na Cepal. Rio de Janeiro: Cofecon-Cepal; Record, 2000. v. I.

PREBISCH, Raul (1949). O desenvolvimento econômico da América Latina e alguns de seus principais problemas. In: BIELSCHOWSKY, Ricardo (Org). Cinquenta anos de pensamento na Cepal. Rio de Janeiro: Cofecon-Cepal; Record, 2000. v. I.

ROCHA, Marco Antônio. Transformações produtivas e patrimoniais no Brasil pós-crise. In: DIMENSÕES estratégicas do desenvolvimento brasileiro. Brasília: CGEE, 2015. v. 4.

RODRIK, Dani. One economics, many recipes: globalization, institutions, and economic growth. New Jersey: Princeton University Press, 2007.

ROSENSTEIN-RODAN, Paul N. Problemas de industrialização da Europa do Leste e do Sudeste. In: AGARWALA, A. N.; SINGH, S. P. (Org.) (1958). A economia do subdesenvolvimento. Rio de Janeiro: Contraponto; Centro Internacional Celso Furtado, 2010.

ROSTOW, Walt W. (1956). A decolagem para o crescimento autossustentado. In: AGARWALA, A. N.; SINGH, S. P. (Org.) (1958). A economia do subdesenvolvimento. Rio de Janeiro: Contraponto; Centro Internacional Celso Furtado, 2010.

SARTI, Fernando; HIRATUKA, Célio. Desenvolvimento industrial no Brasil: oportunidades e desafios futuros. Campinas: Unicamp. IE, 2011. (Texto para Discussão, n. 187).

SARTI, Fernando; HIRATUKA, Célio. Desempenho recente da indústria brasileira no contexto de mudanças estruturais domésticas e globais. Campinas: Unicamp. IE. 2017. (Texto para Discussão, n. 290).

SCHUMPETER, J. Capitalismo, socialismo e democracia. São Paulo: Abril Cultural, 1942.

SINGER, A. Cutucando onças com varas curtas. O ensaio desenvolvimentista no primeiro mandato de Dilma Roussef (2011-2014). Novos Estudos, n. 102, p. 43-71, jul. 2015.

THIRLWALL, Anthony Philip. A plain man's guide to Kaldor's growth laws. Journal of Post Keynesian Economics, v. 5, n. 3, p. 345-358, 1983.

TIMMER, Marcel P.; de VRIES, G. J. Structural change and growth accelerations in Asia and Latin America: a new sectoral data set. Cliometrica, v. 3, n. 2, p. 165- 190, 2009.

UNITED NATIONS CONFERENCE ON TRADE AND DEVELOPMENT - UNCTAD. Trade and Development Report: structural transformation for inclusive and sustained growth. New York and Geneva: United Nations, 2016. 